\title{
Dengue Virus Glycosylation: What Do We Know?
}

\author{
Sally S. L. Yap ${ }^{1}$, Terry Nguyen-Khuong², Pauline M. Rudd ${ }^{2}$ and Sylvie Alonso ${ }^{\text {* }}$ \\ ${ }^{1}$ Department of Microbiology and Immunology, Yong Loo Lin School of Medicine, and Immunology program, Life Sciences \\ Institute, National University of Singapore, Singapore, Singapore, ${ }^{2}$ Analytics Group, Bioprocessing Technology Institute, \\ $A^{*} S T A R$, Singapore, Singapore
}

\section{OPEN ACCESS}

Edited by:

Akio Adachi,

Tokushima University, Japan

Reviewed by:

Takayuki Hishiki,

Tokyo Metropolitan Institute of Medical Science, Japan Béatrice Nal,

Brunel University London United Kingdom Xiaoming Sun,

Ragon Institute of MGH, MIT and Harvard, United States

${ }^{*}$ Correspondence: Sylvie Alonso micas@nus.edu.sg

Specialty section: This article was submitted to Virology,

a section of the journal Frontiers in Microbiology

Received: 28 May 2017 Accepted: 12 July 2017 Published: 25 July 2017

Citation:

Yap SS, Nguyen-Khuong T, Rudd PM and Alonso S (2017) Dengue Virus Glycosylation: What

Do We Know?

Front. Microbiol. 8:1415.

doi: 10.3389/fmicb.2017.01415
In many infectious diseases caused by either viruses or bacteria, pathogen glycoproteins play important roles during the infection cycle, ranging from entry to successful intracellular replication and host immune evasion. Dengue is no exception. Dengue virus glycoproteins, envelope protein (E) and non-structural protein 1 (NS1) are two popular sub-unit vaccine candidates. E protein on the virion surface is the major target of neutralizing antibodies. NS1 which is secreted during DENV infection has been shown to induce a variety of host responses through its binding to several host factors. However, despite their critical role in disease and protection, the glycosylated variants of these two proteins and their biological importance have remained understudied. In this review, we seek to provide a comprehensive summary of the current knowledge on protein glycosylation in DENV, and its role in virus biogenesis, host cell receptor interaction and disease pathogenesis.

Keywords: dengue virus, glycosylation, glycomics, E protein, NS1 protein

\section{DENGUE DISEASE, DENGUE VIRUS AND DENGUE INFECTION CYCLE}

\section{Dengue}

Dengue (DEN) is an emerging arthropod-borne infectious disease which is caused by DENV. According to the World Health Organization (WHO) (2017), DEN cases have continually increased in recent decades. An estimation of DEN infections worldwide has indicated up to 50-100 million cases per year (WHO, 2017). The virus is transmitted primarily by female Aedes aegypti mosquitoes in tropical and subtropical regions. The spread of DEN in non-tropical areas has been associated to the transmission by the secondary vector, A. albopictus mosquito which is able to withstand winter temperature (Gould et al., 2010). Four serotypes of DENV (DENV1-4) have been identified to date and co-circulation of these serotypes has been reported in Asia, Africa, and America (Guzman et al., 2010).

Abbreviations: ADE, antibody-dependent enchancement; C, capsid; CE, capillary electrophoresis; CLEC5A, C-Type Lectin Domain Family 5 Member A; Cryo-EM, cryoelectron microscopy; DC, dendritic cell; DC-SIGN, dendritic cellspecific Intercellular adhesion molecule-3-Grabbing Non-intergrin; DEN, dengue; DENV, Dengue virus; DHF/DSS, dengue hemorrhagic fever/shock syndrome; DI, domain I; DII, domain II; DIII, domain III; E, envelope; Endo H, endoglycosidase H; ER, endothelium reticulum; HILIC, hydrophilic interaction chromatography; HIV, Human immunodeficiency virus; JEV, Japanese encephalitis virus; LC, liquid chromatography; MALDI, Matrix Assisted Laser Desorption Ionization; MR, mannose receptor; NS, non-structural; PNGase F, peptide:N-glycosidase; prM/M, (pre)membrane; WNV, West Nile virus. 
Most DENV infections are asymptomatic or remain as mild febrile illness. A classical DEN fever is diagnosed when the patient shows self-limiting high fever, headache, and muscle/joint pain 3-14 days after a mosquito bite. A small proportion of DEN patients may develop DEN hemorrhagic fever and/or DEN shock syndrome (DHF/DSS) which are life-threatening. The clinical manifestations of DHF/DSS include hemorrhagic fever, vascular permeability and plasma leakage, thrombocytopenia and circulatory failure in DSS. To date, there is no specific treatment for DEN and no licensed anti-DENV drug is available. For severe DEN cases, clinical complications are managed by supportive therapy to avoid mortality. The progression to severe DEN (DHF/DSS) has been linked to a phenomenon known as ADE of infection (Halstead, 2014). The ADE hypothesis postulates that during a secondary heterologous DENV infection, preexisting anti-DENV antibodies bind to but fail to neutralize the virus, and promote increased uptake of sub-neutralized virions by Fcgamma-receptor bearing cells such as DC, macrophages, and monocytes (Kliks et al., 1989; Boonnak et al., 2008). In addition, ligation of Fc receptor stimulates production of Interleukin (IL)10 which in turn suppresses the cellular anti-viral response (Suhrbier and La Linn, 2003). These events lead to increased viral loads which are believed to correlate with disease severity (Vaughn et al., 2000).

To reduce DEN morbidity and eventually eliminate the disease, an effective vaccine is urgently needed. However, the development of DEN vaccine has been greatly hampered by the potential risk of ADE. The only licensed DEN vaccine (CYDTDV) available is a tetravalent, recombinant, live attenuated DEN vaccine developed by Sanofi Pasteur (Guy et al., 2015). The vaccine has shown varied efficacy against different serotypes and in different age groups, with safety issues in children below 9 years of age (Capeding et al., 2014; Villar et al., 2015). In addition, large scale efficacy studies have suggested that this vaccine works best in people with pre-existing DENV immunity (Capeding et al., 2014). Thus, WHO recommendations have limited the use of the CYD-TDV vaccine in geographical settings with high DEN burden and in age group 9-45 years old (WHO, 2017). Clearly, while this first-in-human tetravalent DEN vaccine will certainly provide a wealth of knowledge and improve our understanding of immune correlates of protection, a better vaccine is needed to protect the 3.9 billion people that are at risk of DEN infection. Several promising vaccine candidates are currently under development; some have entered the clinical pipeline [reviewed in (Schmitz et al., 2011)]. It is hoped that they will address the shortcomings of the CYD-TDV vaccine.

\section{Dengue virus and Dengue Infection Cycle}

DENV belongs to the family Flaviviridae of which the members are well known as human pathogens, including WNV, Zika virus, Yellow fever virus, Tick-borne encephalitis virus, JEV, and Hepatitis $C$ virus (HVC). They are enveloped viruses with positive sense, single stranded RNA and many of them are arthropod-borne viruses. Among all flaviviruses, DENV has the highest impact on global disease burden. The virus particle is about $50 \mathrm{~nm}$ in size and the RNA genome $(\sim 10.7 \mathrm{~kb})$ is encapsulated by a protein shell which consists of three structural proteins, namely capsid (C), envelope (E), and (pre)membrane protein (prM/M) (Kuhn et al., 2002).

In order to establish infection, DENV first binds to the host cell receptors via $\mathrm{E}$ proteins on the cell surface. The ligand-receptor interaction initiates uptake of the virion through receptor-mediated endocytosis (Acosta et al., 2014). Inside the acidic late endosome, membrane fusion occurs as the virion envelope fuses with the endosomal membrane (Allison et al., 1995; Modis et al., 2004), followed by uncoating of the nucleocapsid and then release of the viral RNA into the cytoplasm. The RNA genome of DENV is translated into a single polyprotein by host ribosomes and is made of three structural $(\mathrm{C}$, $\mathrm{E}, \mathrm{prM} / \mathrm{M}$ ) and seven non-structural (NS) (NS1, NS2A/B, NS3, NS4A/B, NS5) proteins. The polyprotein is then cleaved by host and viral proteases to release individual viral proteins (Acosta et al., 2014).

The viral genome replication process within the host cell is mainly driven by the NS proteins. NS1 anchors the replication complex to the ER membrane and interacts physically with NS4B (Youn et al., 2012; Muller and Young, 2013). NS2A is responsible for viral RNA synthesis and virion assembly (Xie et al., 2015). NS3 functions as a serine protease, RNA helicase and nucleotide triphosphatase/RNA triphosphatase, and its protease activity is dependent on the cofactor NS2B (Falgout et al., 1991). NS4A has been reported to induce membrane rearrangement within the host cell, thereby assisting the formation of replication vesicles (Miller et al., 2007). NS5 is a multifunctional enzyme with a methyltransferase (MTase superfamily) domain and a RNAdependent RNA polymerase domain (Acosta et al., 2014). During virion assembly, the newly synthesized viral RNA interacts with $\mathrm{C}$ proteins to form the nucleocapsid. A spiky immature virion is formed when $\mathrm{E}$ and prM proteins encounter the nucleocapsid (Yu et al., 2008; Acosta et al., 2014). The maturation process takes place in the trans-Golgi network where prM is cleaved by host furin to generate a smooth surfaced mature virion (Stadler et al., 1997; Yu et al., 2008), which is released into the extracellular environment through the secretory pathway.

\section{PROTEIN GLYCOSYLATION}

\section{What Is Glycosylation?}

Glycosylation is the post-translational modification of biomolecules such as proteins or lipids through the enzymatic attachment of complex oligosaccharide structures to the peptide backbone or lipid anchor (Varki et al., 2015). Over 70\% of the eukaryotic proteome is glycosylated (Dell et al., 2010). The range of complexity of these structures is reflected by their covalent attachment to the protein, the monosaccharide composition of the glycan and combinations of anomeric ring linkages between these monosaccharides. This complexity affects the branching, antennae and topology of the glycan structures, which translates to the overall tertiary and quaternary structure of the glycoprotein. There are two types of protein glycosylation distinguished by their site of attachment on the protein backbone; $\mathrm{N}$-linked glycosylation where the glycan is covalently attached 
to the asparagine (N) (consensus motif; $\mathrm{NxS} / \mathrm{T}$ except where $\mathrm{x}$ is a proline); and O-linked glycosylation where the glycan is linked to the oxygen from some serine $(\mathrm{S})$ or threonine $(\mathrm{T})$ residues of the protein backbone (Chandler et al., 2013; Varki et al., 2015). N-linked glycans share a common chitobiose core structure. Furthermore, N-linked structures fall under three different classes: (1) high mannose, where the non-reducing composition of the glycans are dominated by mannose sugars that extend from the core, (2) complex, where the branching and extension of the glycans from the core is initiated by $N$-acetyl glucosaminyl transferases; and (3) hybrid structures where the core is extended by both high mannose arm and a complex structure on the other arm (Chandler et al., 2013; Varki et al., 2015) (Figure 1).

Such complexity can be found with the isomerism/anomercity of a sugar. Whilst two glycans may have the same composition, the differences of their isomeric linkages can affect the selectivity of their host receptors and thus biology. For example, in the context of avian influenza, the haemagglutinin specifically and exclusively recognizes 2,3-linked sialic acids that are found in the avian host. This is in contrast to 2,6 linked sialic acid normally found in the human host receptors with very low 2,3-linked sialic acid expressed in the lower respiratory tract. Cross reaction between avian $\mathrm{H} 5 \mathrm{~N} 1$ and such sialic acids caused the recent human epidemics (Shinya et al., 2006; Walther et al., 2013).

\section{Glycosylation Pathway in Mammalian and Insect/Mosquito Cells}

Glycosylation is a highly organized process that involves a network of glycotransferases and glycosidases in the ER-Golgi complex that enzymatically synthesize the glycan as well as trim down the structures so as to achieve the refined structure.

In mammalian cells, $N$-glycosylation takes place predominantly within the ER. Briefly, the initial stages of glycosylation involve the enzymatic synthesis of dolicholphosphate-NAcGlcNAc $\mathrm{Man}_{9} \mathrm{Glc}_{3}$ which usually takes place across the membrane of the ER. This involves firstly the enzymatic synthesis of dolichol-P-P-GlcNAc $\mathrm{Man}_{5}$, before this is "flipped" across the membrane into the ER lumen where further monosaccharides are added (Shi and Jarvis, 2007; Dell et al., 2010). The NAcGlcNAc ${ }_{2} \mathrm{Man}_{9} \mathrm{Glc}_{3}$ is transferred to the appropriate $\mathrm{NxS} / \mathrm{T}$ motif of the protein via the oligosaccharyltransferase as the incipient protein is being translated. As the $N$-glycans transition through the ER-Golgi complex, a series of glycosidases trim down the mannose residues before glycotransferases present in the Golgi extend the antennae of the glycans to produce larger hybrid or complex structures (Varki et al., 2015). In contrast to $N$-glycosylation, $\mathrm{O}$-glycosylation occurs entirely in the Golgi apparatus. It does not involve any glyco-lipid intermediates and no glycosidases appear to be involved in their synthesis and processing.

Within the insect kingdom, glycosylation is far simpler yet interestingly insect are able to produce elaborate protein glycosylation in a restricted fashion compared to glycosylation of higher eukaryotes (Rendić et al., 2008). Most our knowledge in insect glycosylation was derived from studies performed on Drosophila melanogaster and baculoviral-insect systems.
In fact, the bulk of mammalian glycoproteins expressed and/or purified in insect cells have used cell lines from Spodoptera frugiperda (sf9, sf21) or Trichoplusia ni (High five) (Rendić et al., 2008). Glycoproteins derived from these insect cell systems display glycans that contain predominantly high mannose type structures. However, the long belief that these high mannose and paucimannosidic N-linked structures are the dominant forms in insect-cell derived glycoproteins has been recently challenged by the advent of high resolution glyco-analytical tools which were able to identify glyco-epitopes such as [alpha]1-3 fucosylation (Hsu et al., 1997; Takahashi et al., 1999; Rudd et al., 2000) and double core fucosylated structures ([alpha]1-3 and [alpha]1-6 fucosylation on the core GlcNAc) (Staudacher et al., 1992; Rendic et al., 2006). There were also reports of the extension of the [alpha]1,3-arm of the chitobiose core as opposed to the [alpha]1-6 arm extension found in most mammalian cell lines (Kubelka et al., 1993). Higher complex $N$-glycans can be found in many insectderived N-linked glycoproteins, however, if grown in serum free media, lysed cell extracts from sf9 and High five cells do lack the nucleotide donors for sialic acid (CMP-NeuAc) (Rendić et al., 2008). Further to this, the presence of a truncated trimannosyl $N$-glycan with an [alpha]1,6-linked fucose was reported (Shi and Jarvis, 2007; Rendić et al., 2008). Extensive work has shown that such structures are the result of the action of an endogenous hexosaminidase specific for the NAcGlcNAc[beta]1,2-Man structure rather than low activity of

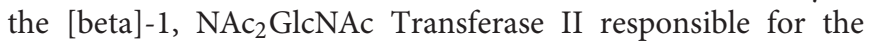
extension of the mannose arms of complex structures (Kubelka et al., 1994).

Studies performed with mosquito cell lines A. albopictus and A. aegypti showed that glycoproteins produced in these cell lines display predominantly high mannose and pauci-mannosidic structures (Hsieh and Robbins, 1984). Interestingly, within these initial experiments, the presence of mannosidase-resistant structures was observed (Rhomberg et al., 2006).

\section{Glycomics}

Glycomics as a field has experienced a significant maturation from low to high resolution analysis. In the past decades, scientists have mostly relied on digestive enzymes (Johnson et al., 1994; Mondotte et al., 2007; Hacker et al., 2009), chromatography (Johnson et al., 1994), lectin-binding assay (Johnson et al., 1994; Hacker et al., 2009) and radioactive labeling (Smith and Wright, 1985) to study the glycan structure on glycoproteins. Enzymatic digestion by Endo $\mathrm{H}$ and peptide: $N$-glycosidase (PNGase F) remains the most popular method due to its simplicity and allows the investigator to determine whether the glycan structure is asparagine linked (N-linked). In this approach, purified glycoprotein is subjected to specific enzymatic digestion prior to separation on SDS-PAGE. After cleavage of the attached oligosaccharide chains, the digested protein migrates ahead of the undigested form due to a lower molecular weight. Enzymatic digestion of glycoproteins reveals, however, relatively little information on the glycan structure.

Over the recent decade, glycan analysis has dramatically improved through developments in fluorescent labeling, 


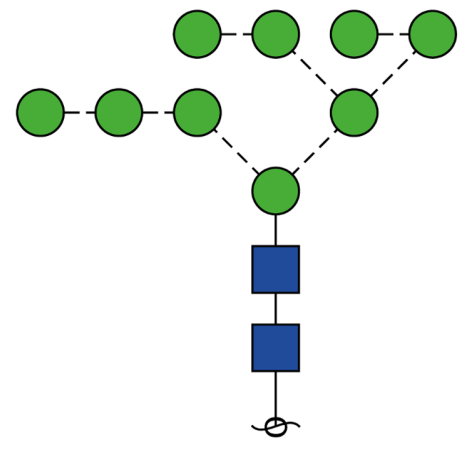

High Mannose

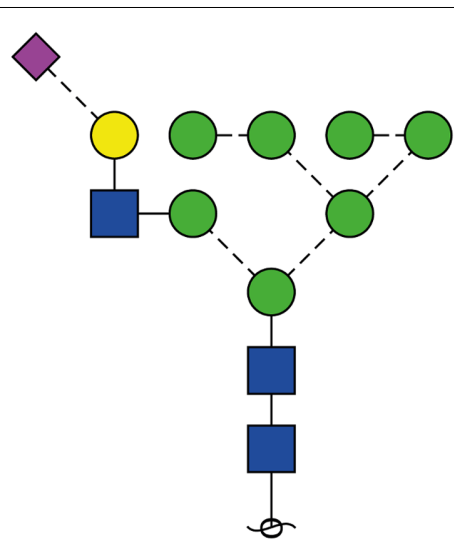

Hybrid

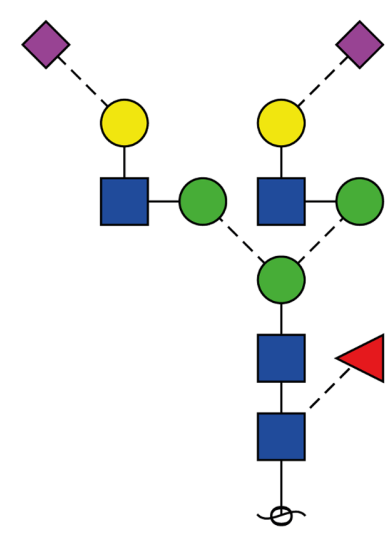

Complex

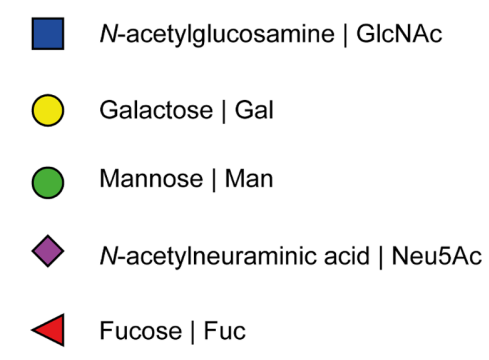

CFG representation

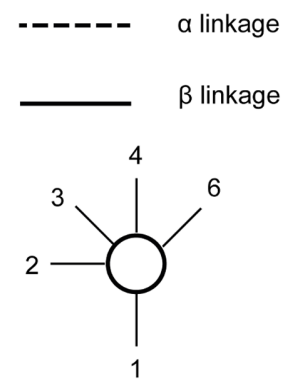

Linkage

FIGURE 1 | Types of N-glycans. High mannose, hybrid and complex N-linked glycans are enzymatically attached to the N-X-S/T sequence of the glycoprotein.

LC and mass spectrometry. There is an abundance of techniques such as LC, CE and mass spectrometry which are available for glycomic analysis. For LC and CE, the field has benefited from labels such as 2-AB, 2-AA (LC separation) and 9-Aminopyrene-1,4,5-trisulfonic acid (CE separation), whereby glycans are tagged at a glycan's reducing end and the identity of these glycans is assigned based on their retention time behavior across a HILIC or CE, respectively (Rudd and Dwek, 1997; Callewaert et al., 2001). Approaches coupling fluorescence with mass spectrometry (FLR-MS) have helped increase the efficiency of glycomic approaches. In such a platform, the retention time and fluorescence are usually coupled with mass detection to add further confirmation (Houel et al., 2014; Zhang et al., 2016). The use of exoglycosidase arrays adds further confidence to a glycan's structure elucidation and can help to identify co-eluting glycan species (Marino et al., 2010). The evolving development of glycan labeling has meant that newer, faster labeling and highly sensitive labels such as procainamide or Rapidfluor Mass Spectrometry (RFMS) label can increase the throughput and efficiency of a glycomic analysis.

Various modes of mass spectrometry have been applied to the analysis of released glycans. The most common are MALDI and electrospray ionization. MALDI is a straight-forward method that often requires methods such as permethylation and esterification to increase signal intensity and stabilize labile glycans that contain sialic acids. Electrospray ionization involves a milder desolvation technique and coupled with LC methods and further fragmentation of the molecule, provides high resolution techniques to qualitatively characterize a glycome (Nguyen-Khuong et al., 2015). Detection of glycan fragments which result from fragmentation along the glycosidic bonds (detected in positive mode) and cross-ring (detected in negative mode) (Harvey et al., 2004; Everest-Dass et al., 2012) help to understand the composition and topology of the glycan without the need to adulterate the glycan through derivatization.

Glycoproteomics allows investigators to understand the degree of glycosylation on various sites of the glycoprotein. The platform is adapted from proteomics and as such relies heavily upon mass spectrometry and substantial data analysis. Whilst most glycoproteomic methodologies follow similar approaches to proteomics such as trypsin digestion and analysis, key to any glycoproteomics method is the enrichment of glycopeptides (Mysling et al., 2010; Kolarich et al., 2012). This is important to reduce the ion suppression from peptide mass spectrometry signals without enrichment. This 
can be performed via HILIC chromatography, in which the enrichment is centered upon exploiting a glycan's hydrophilicity. Fragmentation data is vital to glycopeptide identification and data analysis must be able to exploit the information which can come from fragmentation modes such as collisionally induced dissociation (CID), high collisional dissociation or electron transfer dissociation/electron transfer high collisional dissociation (ETD/EtHCD) available to the investigator (Scott et al., 2011; Thaysen-Andersen et al., 2016; Stavenhagen et al., 2017). Depending on the strength of fragmentation, information such as glycan composition, site of attachment and peptide backbone are all able to be divulged from a single spectrum (Yang et al., 2016).

\section{Biological Importance of Glycosylation and Role in Viral Pathogenesis}

Glycans either directly or indirectly have diverse biological functions which span but are not limited to inflammation, immunology, infectious diseases, metabolism, embryogenesis, cancer biology and neurodegeneration. At the protein level, glycosylation is responsible for correct protein folding/structure, protein trafficking and stability, receptor/ligand recognition as well as increasing its half-life in the blood stream (Park et al., 2005; Bork et al., 2009; Sumer-Bayraktar et al., 2011; Hart, 2013; Palmisano et al., 2013). At the cellular level, complex sugar structures modulate receptor functions and thus are integral to regulate normal cell-cell, cell-substrate communication and adhesion (Vercoutter-Edouart et al., 2008; Varki et al., 2015). Glycosylation disorders can adversely affect immunity and cancer development. From an immunological perspective, all living cells are covered by a dense glycocalyx and indeed, pathogens and foreign objects must deal with this complex forest of cell surface glycoconjugates upon entering the host (Pickles et al., 2000; Rodrigues et al., 2015).

Viruses do not possess their own glycosylation machinery and by virtue of their opportunistic nature, are heavily dependent upon the glycosylation machinery of the host cell to glycosylate their proteins. HIV, Influenza virus, Hendra virus, Severe acute respiratory syndrome coronavirus (SARS-CoV), Hepatitis viruses and WNV are examples of viruses for which glycosylation was shown to be critical to their stability, infectivity and antigenicity (Mir-Shekari et al., 1997; Vigerust and Shepherd, 2007; Medina et al., 2013; Doores, 2015). Firstly, glycosylation can be involved in receptor binding. This is exemplified by HIV and DENV which rely on high mannose type glycosylation to bind to their MRs or DC-SIGN that are present on host immune cells (Cambi and Figdor, 2003; Cambi et al., 2004). Furthermore, glycosylation is required to facilitate proper protein folding and trafficking of the viral membranes using the host chaperones such as calnexin and/or calreticulin proteins (Meunier et al., 1999; Land and Braakman, 2001; Slater-Handshy et al., 2004). Importantly, glycosylation is a means to evade immune recognition within the host by changing glycan sites (Medina et al., 2013), which in turn can increase the diversity of the glycosylation on the virus. In addition, the glycan structure has been reported to mask particular antigenic sites from recognition by neutralizing antibodies (Doores, 2015; Walls et al., 2016).

\section{GLYCOPROTEINS IN DENV AND OTHER FLAVIVIRUSES}

\section{Envelope (E) Protein}

The external protein shell of DEN virion consists of 180 copies of E (53-56 kDa) and prM glycoproteins whereby only E proteins are exposed on the surface (Kuhn et al., 2002). Extensive research over the years has revealed multiple functions of $\mathrm{E}$ protein in host receptor attachment, cellular uptake of virion and membrane fusion. E protein forms dimers on the virion surface (Kuhn et al., 2002). The ectodomain of each $\mathrm{E}$ monomer without the transmembrane domains and membrane-associated "stem" region displays an elongated structure under Cryo-EM, which is further defined into three distinct domains (Domains I, II, and III) (Rey et al., 1995). The central N-terminal DI separates the dimerization DII from the C-terminal DIII. DIII has been proposed to be the receptorbinding domain (Kuhn et al., 2002) whereby neutralizing monoclonal antibodies against DIII most efficiently block virus initial attachment to mammalian cells (Crill and Roehrig, 2001).

The fusion peptide located at the tip of DII is essential for endosomal membrane fusion and is essential for virus entry (Allison et al., 2001; Kuhn et al., 2002; Huang et al., 2010). Dimerization of $\mathrm{E}$ proteins at neutral $\mathrm{pH}$ positions the fusion loop into a hydrophobic pocket formed by DI and DIII of the adjacent E monomer. This helps to prevent premature exposure of the fusion loop before endocytosis of the virion by a new host cell. DI forms part of the flexible hinge region which facilitates structural rearrangement of $\mathrm{E}$ protein during virion maturation and fusion process (Zhang et al., 2004). Inside the acidic endosome, the $\mathrm{pH}$-dependent hinge at the DI-DII interface (Allison et al., 1995; Modis et al., 2003) allows E dimer to dissociate and rearrange into a trimeric form which serves as a pre-fusion intermediate promoting membrane fusion (Modis et al., 2004).

In the ER lumen of the host cell, membrane-associated $\mathrm{E}$ protein is generated after co-translational processing of the viral precursor polypeptide by host Signalase (Acosta et al., 2014). The newly synthesized $\mathrm{E}$ protein rapidly heterodimerizes with prM (Lorenz et al., 2002) and three prM-E heterodimers further oligomerize to form a total of sixty heterotrimeric prME spikes per subviral particle (Konishi and Mason, 1993; Zhang et al., 2003). This higher-order oligomer has been proposed to represent the preassembly complex (Wang et al., 1999). Translocation of this complex from ER to Golgi is critical as the transition from immature to mature virion is completed only in the trans-Golgi network, where the spiky prM-E trimers are rearranged into 90 flat dimers in a head-to-tail orientation on the virion surface (Kuhn et al., 2002; Zhang et al., 2003).

In the ER, DENV E protein undergoes N-linked glycosylation at two asparagines, N67 and N153 located in DII and DI, respectively (Chambers et al., 1990; Johnson et al., 1994; Hacker 
et al., 2009). The N67 glycosylation site is unique to DENV and has been proposed to interact directly with DC-SIGN, one of the host cell receptors (Pokidysheva et al., 2006) (see Virus Attachment to Cell Surface and Cell Entry Process). In contrast, N153 (N154 in other flaviviruses) represents the conserved glycosylation site in the family Flaviviridae. High resolution crystal structure of Tick-borne encephalitis virus $\mathrm{E}$ dimer shows the N154-oligosaccharide chain projected overhead of the hydrophobic groove where the fusion loop fits in, suggesting that it functions as an "epitope shield" over the fusion loop to stabilize the dimer contacts (Rey et al., 1995). Consistently, DENV2 and DENV3 mutant viruses lacking N153glycans due to a single point mutation within the glycosylation motif displayed elevated fusion $\mathrm{pH}$ threshold compared to their parental counterpart (Guirakhoo et al., 1993; Lee et al., 1997). The authors proposed that the altered fusion activity of these mutants was likely due to instability of the $\mathrm{E}$ dimers.

The glycan structure on DENV E protein has been studied using digestive enzymes (Johnson et al., 1994; Mondotte et al., 2007; Hacker et al., 2009), chromatography (Johnson et al., 1994), lectin-binding assay (Johnson et al., 1994; Hacker et al., 2009) and radioactive labeling (Smith and Wright, 1985). Endo $\mathrm{H}$ and PNGase F-enzymatic digestion revealed the presence of $N$-glycosylation in DENV E protein. No O-linked glycan has been detected to date (Johnson et al., 1994). In mosquito cell-derived virions, the $N$-glycans attached to E protein display heterogeneity in structure and sugar composition where high mannose and paucimannose with terminal mannose residues are the dominant glycoforms (Figure 2A) (Smith and Wright, 1985; Johnson et al., 1994; Hacker et al., 2009).

Recently mass spectroscopy has been applied to DENV glycoprotein studies to provide a comprehensive and detailed profile of the glycan moieties (Dubayle et al., 2015; Lei et al., 2015). Using an integrated mass spectroscopy strategy consisting of lectin microarray and MALDI-Time of Flight Mass Spectrometry (MALDI TOF-MS), Lei et al. (2015) have successfully determined the detailed composition of $N$-glycans attached to the $\mathrm{E}$ protein from mosquito cell derived mature DENV2. Among the 19 distinct $N$-glycans detected, 15 contain terminal galactosylation while the remaining glycans were identified as high mannose type, complex type, fucosylated and sialylated $N$-glycans. In a separate study, the $N$-glycans from DENV1-4 (vaccine CYD-TDV) produced in mammalian Vero cells have been reported to consist of high mannose, complex and hybrid glycans with complex glycans as the major glycan species (Figure 2A) (Dubayle et al., 2015). By performing in-gel proteolysis of E-protein, site specific $N$-glycans have been determined. Sialylated complex glycans and high mannose (6-8 residues) glycans were detected at N153 in all DENV except for DENV2. Besides, most of the complex or hybrid glycans at N153 were found fucosylated. Interestingly, fucosylated glycans were detected only at N153 but not at N67 across all four DENV serotypes. Since high mannose binding DC-SIGN interacts only with N67 glycans on the viral surface (Pokidysheva et al., 2006) and N153-glycan is dispensable for virus production in mosquito and mammalian cells (Bryant et al., 2007), this suggests that N153 glycans may serve a distinct function from N67 glycans in DEN pathogenesis possibly via interaction with an unknown fucose binder or act as a viral glycan shield. For N67 specific glycans, DENV2 was reported to have a different sugar composition from the other three DENV serotypes (Dubayle et al., 2015) whereby a higher content of complex or hybrid glycans was found in DENV2. High mannose glycans were detected as the main glycan species for DENV1, 3 and 4 . In addition, sialylated $N$-glycan was detected only in DENV2 at this site. The differential glycosylation pattern between DENV2 and DENV1, 3, 4 may impact on various aspects of dengue pathogenesis including virus tropism, virus fitness, and induction of host responses (see Role of Glycosylation in DENV Life Cycle).

\section{Non-structural Protein 1 (NS1)}

Non-structural Protein 1 (NS1) was first identified as a nonhemagglutinating, soluble complement-fixing antigen in the brain and serum from DENV2-infected mice (Brandt et al., 1970; Smith and Wright, 1985). NS1 has a molecular weight range of $46-55 \mathrm{kDa}$ depending on its glycosylation status. It is a multifunctional glycoprotein which presents in different oligomeric forms and locates at various cellular compartments (Westaway and Goodman, 1987; Flamand et al., 1999).

Non-structural Protein 1 monomer consists of three structural domains namely a $\beta$-roll dimerization domain, a wing domain and a $\beta$-ladder domain (Akey et al., 2014). The monomer structure is stabilized by six intramolecular disulfide bonds and no intermolecular disulfide bond has been identified in dimeric NS1 (Winkler et al., 1988). However, any one of the three cysteine residues at the $\mathrm{C}$-terminal has been reported to be important for dimer formation (Pryor and Wright, 1993). The $\beta$-roll domain and part of the extended wing domain form a hydrophobic protrusion surface that acts as the ER membrane and replication complex (NS4B) interacting site, which is critical for viral RNA replication (Youn et al., 2012; Akey et al., 2014).

NS1 dimer is formed when two $\beta$-roll domains dimerize at the center and these dimers tend to trimerize resulting in hexameric NS1 (Flamand et al., 1999; Gutsche et al., 2011; Muller et al., 2012). The NS1 hexamer crystal structure revealed a barrel-shaped oligomer with a central open channel. Three dimers are arranged symmetrically in a way such that the $\beta$-roll domains are entirely facing inwards and the channel interior is lined by the hydrophobic protrusion surface contributed by each dimeric component (Akey et al., 2014). The hydrophobic lining allows the NS1 hexamer to be secreted as a lipoprotein whereby the lipid cargo is loaded into the central channel (Gutsche et al., 2011). In contrast to the $\beta$-roll domains, glycosylation sites and most of the linear epitopes of NS1 identified are facing outward, representing the most accessible parts of NS1 hexamer by host antibodies (Akey et al., 2014).

Intracellular NS1 is predominantly in dimeric form whereas secreted NS1 is mainly in hexameric form (Figure 2B) (Flamand et al., 1999). During protein synthesis, NS1 is cleaved from the viral polypeptide and translocated into the ER lumen. 
A
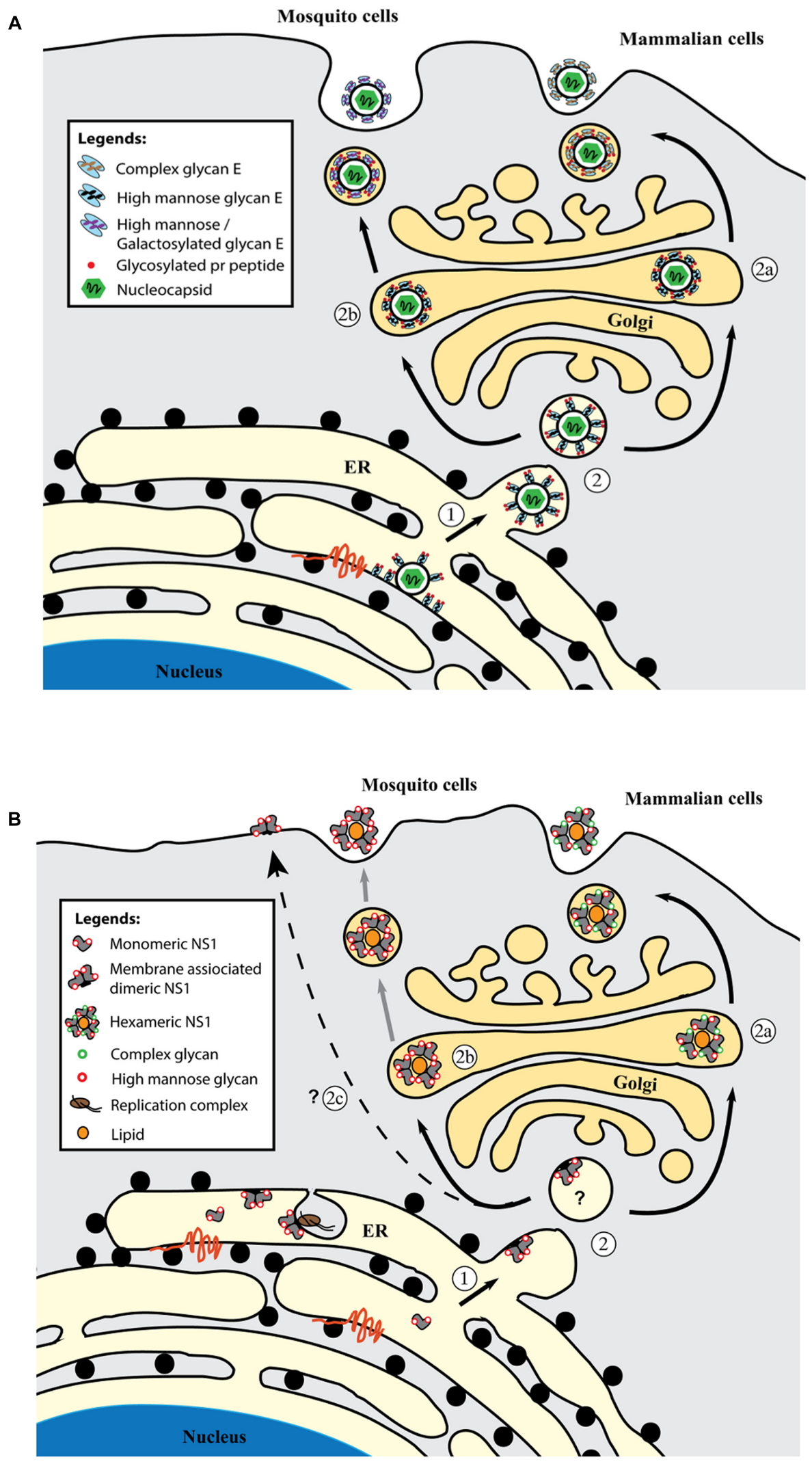

FIGURE 2 | Continued 
FIGURE 2 | Glycosylation of DENV E (A) and NS1 (B) proteins in mammalian cells and mosquito cells. (A) In ER, newly synthesized E protein is glycosylated and heterodimerizes with prM protein to form a higher order oligomeric preassembly complex. The immature virus particle with prM-E spikes is formed when the nucleocapsid associates with prM-E-rich membranes which buds into the ER lumen (1). The glycans remain of high mannose type on the immature virus particle as it is translocated to Golgi apparatus along the secretory pathway (2). The conformational rearrangement of prM-E spikes and cleavage of prM by host protease furin occurs in the Golgi to produce a mature, smooth virus particle. In mammalian cells, the glycans are further processed and modified into complex glycans before the virus particle is released to the extracellular milieu (route 2a). In mosquito cells, majority of the glycans are high mannose or galactosylated due to the different glycosylation enzymes expressed in insect cells (route 2b). High mannose glycan on the E protein, particularly the N67-glycan facilitates DC-SIGN(+) cell infection and virus propagation. The function of complex glycan on E protein is currently unknown. The glycosylated pr peptides are bound to E protein after furin cleavage and only dissociate at neutral pH in the extracellular milieu. (B) Monomeric NS1 protein is glycosylated with high mannose glycans at N130 and N207. The monomer rapidly dimerizes in the ER and membrane-associated NS1 dimers (1) are involved in virus RNA replication. Three NS1 dimers form a soluble hexameric NS1 but the exact location of hexamer formation remains unknown (2). In mammalian cells, the N130 glycans are modified into complex glycans before the soluble NS1 hexamer is secreted out of the cells (route 2a). In mosquito cells, generation of complex glycans doesn't happen and the lack of complex glycans (N130) on NS1 hexamer affects hexamer stability and greatly reduces its secretion (route 2b). A subset of dimeric NS1 are found on the infected cell surface but the trafficking pathway has yet to be determined (route 2c). High-mannose glycan at N207 stabilizes NS1 dimer.

The soluble monomer undergoes dimerization to gain partial hydrophobicity (Flamand et al., 1999), allowing membrane association of NS1 dimer in the absence of a transmembrane domain (Winkler et al., 1989). The exact mechanism of NS1 hexamer formation remains unclear and two possible locations have been proposed including along the Golgi secretory pathway, or immediately after dimerization at the ER (Muller and Young, 2013).

The functions of NS1 are closely associated to its cellular location throughout the virus replication cycle. ER membraneassociated dimeric NS1 has been found to co-localize with viral dsRNA (Mackenzie et al., 1996). Circulating hexameric NS1 is able to bind to the plasma membrane of mammalian cells via the interaction between its $N$-glycans and cell surface glycosaminoglycans, heparin sulfate and chondroitin sulfate E (Avirutnan et al., 2007). Recently, it has been reported that hexameric NS1 contributes to disease pathogenesis of severe DEN (Beatty et al., 2015; Modhiran et al., 2015). The soluble protein acts as a viral toxin that induces pro-inflammatory cytokine response and vascular leakage via Toll-like receptor 4 expressed on immune cells and endothelial cells (Modhiran et al., 2015). Beatty et al. (2015) showed that NS1 vaccination protects mice from NS1-induced vascular leakage which was independent of complement components.

Glycosylation of DENV NS1 occurs right after its cleavage in the ER (Winkler et al., 1988) at two asparagines, N130 and N207 (Putnak et al., 1988; Winkler et al., 1989; Flamand et al., 1999). These two $N$-glycosylation sites are conserved in the family Flaviviridae. Recently, a less conserved glycosylation site at N175 has been reported in WNV, St. Louis encephalitis virus and Murray Valley encephalitis virus but is absent in all four serotypes of DENV (Akey et al., 2014). Intracellular and extracellular DENV NS1 display different types of $N$-glycans as the oligosaccharides undergo modification during the maturation process (Winkler et al., 1989; Pryor and Wright, 1994; Flamand et al., 1999). Intracellular dimeric NS1 N-glycans are of high mannose composition regardless of the host cell type (mammalian or mosquito cell) (Mason, 1989). On the other hand, in extracellular hexameric NS1, the N130-glycans consist of complex oligosaccharides whereas the N207-glycans are made of high mannose type sugar chains (Mason, 1989; Pryor and Wright, 1994; Flamand et al., 1999). As dimeric NS1 passes through the Golgi apparatus, two N130-glycans are further modified into the Endo H-resistant, multi-branched complex type before the protein is released (Winkler et al., 1989). The differential modification at these two sites is due to the inaccessibility of N207-glycan by Golgi-resident enzymes after the dimerization of NS1 (Flamand et al., 1999).

\section{PrM/M Protein}

In the DENV replication cycle, prM interacts with $\mathrm{E}$ protein and acts as a chaperone to ensure proper $\mathrm{E}$ protein folding (Lorenz et al., 2002) and to prevent premature fusion of the virus particle along the secretory pathway by concealing the E fusion loop (Li et al., 2008; Yu et al., 2009). Glycosylation of the prM/M glycoprotein in DENV has not been extensively studied. The protein is glycosylated at N69 (Table 1) with circumstantial evidence for $\mathrm{N}$-linked glycosylation at sites 7, 31, and 52 (Courageot et al., 2000). It was found that $\alpha$-glucosidase inhibitor reduced the amount of prM-E heterodimer, suggesting the $N$-glycans are required for productive folding pathway of these glycoproteins (Courageot et al., 2000). Triglucosylated $N$-glycan at N68 of DENV1 affects the folding of prM by causing a delayed formation of prM-E heterodimer (Courageot et al., 2000).

\section{ROLE OF GLYCOSYLATION IN DENV LIFE CYCLE}

$N$-glycosylation on both E and NS1 proteins has been shown to play important roles throughout the DENV infection cycle from virion attachment, entry, maturation, assembly to secretion.

\section{Virus Attachment to Cell Surface and Cell Entry Process}

Carbohydrate chains on the DENV E proteins play a critical role in host cell infection at the early step of host receptor binding. Indeed, virus attachment and penetration into mammalian and mosquito cells were blocked by pre-incubation of virus with Concanavalin A, a plant lectin that binds to alpha-linked terminal mannose of high mannose or hybrid glycans (Hung, 1999). Lectins are a group of proteins that recognize carbohydrates through a carbohydrate recognition domain [reviewed in 
TABLE 1 | Glycosylation of DENV proteins.

\begin{tabular}{|c|c|c|c|c|}
\hline Serotypes* & DENV 1 & DENV 2 & DENV 3 & DENV 4 \\
\hline C & NA & NA & NA & NA \\
\hline $\operatorname{PrM} \pm$ & \multicolumn{4}{|c|}{ N64-69 } \\
\hline$E$ & N67 and N153 & N67 and N153 & N67 and N153 & N67 and N153 \\
\hline NS1 & N130 and N207 & N130 and N207 & N130 and N207 & N130 and N207 \\
\hline NS2A & $\mathrm{Va}$ & $\mathrm{Va}$ & $\mathrm{Va}$ & $\mathrm{Va}$ \\
\hline NS2B & NA & NA & NA & NA \\
\hline NS3 & $\mathrm{Va}$ & Va & $\mathrm{Va}$ & $\mathrm{Va}$ \\
\hline NS4A & $\mathrm{Va}$ & Va & $\mathrm{Va}$ & $\mathrm{Va}$ \\
\hline NS4B & $\mathrm{Va}$ & $\mathrm{Va}$ & $\mathrm{Va}$ & $\mathrm{Va}$ \\
\hline NS5 & $\mathrm{Va}$ & $\mathrm{Va}$ & $\mathrm{Va}$ & $\mathrm{Va}$ \\
\hline
\end{tabular}

NA, not applicable (NxT/S motif is not identified).

Va, the presence and number of NXT/S motifs vary among serotypes.

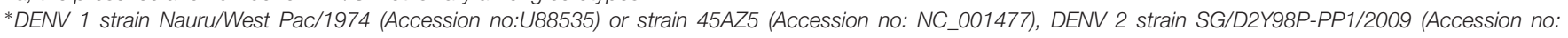

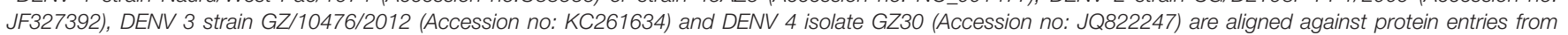
Conserved Domain Database (CDD) or UniProt using BLAST (Basic Local Alignment Search Tool).

\pm The $N$-glycosylation site is located at residue 64 to 69 depending on the serotype.

(Zelensky and Gready, 2005)]. To date, various lectin families such as C-type, P-type, L-type, Galectin and Calnexin have been shown to interact with viral components (Liu et al., 2015). C-type lectins are particularly important for DENV infection as they have been shown to be involved in host cell attachment and disease pathogenesis (see Disease Pathogenesis).

The cell membrane-anchored C-type lectin DC-SIGN has been identified as host cell receptor for many viruses (Liu et al., 2015), among which DENV infects DC and monocyte via DC-SIGN (Navarro-Sanchez et al., 2003; Tassaneetrithep et al., 2003). The interaction between DC-SIGN and DENV can be inhibited by the addition of mannose and mannan (Chen et al., 2008) and has been further examined at the molecular level by structural analysis. Cryo-EM data of DENV/DCSIGN complexes reveals that the carbohydrate recognition domain of DC-SIGN interacts directly with the N67-glycan of E dimers (Pokidysheva et al., 2006). Consistently, lectin (HHA)-resistant DENV which lacks both $N$-glycosylation sites on $\mathrm{E}$ protein failed to infect DC-SIGN(+) DC, in contrast to productive infection and replication in DC-SIGN $(-)$ and carbohydrate-independent cells such as Vero, Huh7, C6/36 and Baby Hamster Kidney fibroblasts (BHK-21) (Alen et al., 2012). The presence of N67-glycan on E protein also allows DENV to infect endothelial cells in liver and lymph node via DC-SIGN-related proteins known as DC-SIGNR and L-SIGN, the close homologues of DC-SIGN (Tassaneetrithep et al., 2003; Alen et al., 2012). In addition to DC-SIGN, MR has been identified as another C-type lectin utilized by all four serotypes of DENV to infect macrophages and DC (Miller et al., 2008). Both MR and DC-SIGN bind to DENV E protein with high affinity $\left(K_{\mathrm{D}}\right.$ in the sub-nanomolar range) (Lo et al., 2016), despite a different ligand specificity for these two host receptors (Miller et al., 2008). MR shows a preferential binding to terminal mannose, fucose and $\mathrm{N}$-acetyl glucosamine while DC-SIGN binds to high-mannose oligosaccharides (Miller et al., 2008). As DC-SIGN and MR have been proposed to be the primary host receptors for DENV during infection (Lo et al., 2016), the engagement to these C-type lectin receptors with diverse glycoforms of E protein may allow DENV to infect a wide range of host cells.

In contrast and interestingly, N67 deglycosylated (N67-) DENV1 and DENV2 were found to display enhanced infectivity in mosquito cells (C6/36) compared to wild type (WT) (Ishak et al., 2001; Lee et al., 2010; Alen et al., 2012). For mosquito cells, the entry mode employed by Flavivirus (DENV and JEV) was shown to involve membrane fusion instead of receptormediated endocytosis (Hase et al., 1989a,b). Hence, it is possible that absence of the N67-glycans from the virion surface reduces steric hindrance and therefore promotes cell membrane attachment and membrane fusion. Finally, N153 deglycosylated $\left(\mathrm{N}_{153}{ }^{-}\right)$DENV mutant displayed reduced infectivity (10-fold lower) in both mammalian and mosquito cells compared to WT, possibly due to impaired virus entry process (Lee et al., 1997; Hacker et al., 2009), whereby loss of the N153-glycan affected the conformational stability of $\mathrm{E}$ proteins and led to premature exposure of the fusion peptide (Yoshii et al., 2013).

\section{Production of Infectious Virus Particles E Protein Glycosylation}

Early studies on DENV E protein showed that $N$-glycosylation is not essential for virus replication in mosquito cells (Bryant et al., 2007; Mondotte et al., 2007). Instead, loss of the N67glycosylation site through site directed mutagenesis (N67Q) in E protein was sufficient to render DENV2 (strain 16681) growth defective in BHK-21 cells, a DC-SIGN(-) cell line (Bryant et al., 2007). Direct transfection of N67Q mutant RNA into BHK-21 cells neither produced intracellular viral antigen nor released new virus progeny. The lack of virion release may be due to impaired virion secretion along the ER-Golgi secretory pathway in the absence of N67-glycan tag on E protein. However, the same mutant replicated and grew comparably to WT counterpart in C6/36 mosquito cells in vitro and in A. aegypti mosquito in vivo (Bryant et al., 2007), thus supporting that $N$-glycosylation of $\mathrm{E}$ protein at position N67 is essential for productive infection in 
mammalian cells only, consistent with earlier studies (Bryant et al., 2007; Mondotte et al., 2007).

Further investigation on the importance of the $N$-glycosylation motif was done by Lee et al. (2010) through extensive point mutation within the conserved $\mathrm{N}-\mathrm{x}-\mathrm{T} / \mathrm{S}$ motif of DENV2 (strains PUO-218 and NGC), whereby the conserved residue T69 was replaced with residues of different side chain propensity. Replacement of T69 by a larger and more hydrophobic residue (leucine and valine) either by molecular cloning (Lee et al., 2010) or by passaging the virus under selection pressure (Alen et al., 2012) generated viable virus that retained efficient growth in BHK-21 and Vero cells in the absence of N67 glycan. In addition, N67Q/D mutant virus generated in strain PUO-218 propagated in mammalian cells at reduced growth rate, which is inconsistent with previous studies carried out with DENV2 strain 16681 (Bryant et al., 2007; Mondotte et al., 2007). The differential and virus strain-dependent outcome led to the hypothesis that in the absence of N67 glycosylation, the aminoacid composition of the DII region determines virus survival in mammalian cells (Lee et al., 2010). Multiple sequence alignment showed indeed that strain 16681 differed from strains PUO-218 and NGC at two positions, arginine (R)120 in DII and T170 in DI (Figure 3). Uncharged polar threonine replaces charged R120 and hydrophobic isoleucine (I) replaces T170 in strains PUO-218 and NGC. It is possible that the presence of hydrophobic residues facilitates protein folding even without the glycan tag for chaperone-assisted folding and followed by productive protein secretion. Nevertheless, structural comparison of the WT strains and their respective mutants needs to be carried out to confirm this hypothesis.

In contrast to the varying outcomes obtained with N67 mutant viruses and their ability to grow in mammalian cells, it has been consistently reported that these virus variants replicate, propagate in mosquito cells but produce lower virus titers compared to WT (Bryant et al., 2007; Mondotte et al., 2007; Lee et al., 2010).

N153-glycan on E protein is important but not essential for DENV survival in mosquito cells. Successive passages (as low as two passages) of DENV in C6/36 cells in vitro resulted in mutation at T155 which ablates the N153-glycosylation motif; however, the non-glycosylated variant was able to propagate in mosquito cells (Lee et al., 1997). N153- DENV grows in both mammalian cells and C6/36 cells and produce lower virus titer than its WT counterpart (Bryant et al., 2007; Lee et al., 2010), which could be due to defective virus budding. Consistently, in a study using transmission electron microscopy, it was shown that virus budding of WT WNV occurs at the plasma membrane while the mature progeny of $\mathrm{N}_{154^{-}}$mutant scatters at the smooth membrane vesicle within swollen ER lumen without budding (Li et al., 2006).

\section{NS1 Protein Glycosylation}

N130A NS1 mutant virus of DENV1 (Tajima et al., 2008) and DENV2 (NGC) (Pryor et al., 1998) failed to generate viable virus in both mammalian and mosquito cells. Mutation at N130 in DENV4 NS1 caused reduced viral growth in mammalian cells and C6/36 cells (Pletnev et al., 1993). However, N130Q NS1 mutant of DENV2 (16681) produced infectious virus with a similar titer as the WT virus in mammalian cells but with a reduced titer in C6/36 cells (Crabtree et al., 2004). Removal of glycan from N207 in DENV1 and DENV2 (16681) NS1 protein produced similar growth and virus titers compared to WT in mammalian cells despite a delayed cytopathic effect (Crabtree et al., 2004; Tajima et al., 2008), which is not consistent with the observation on DENV2 (NGC) (Pryor et al., 1998). Double mutation attempts (N130Q/N207Q and T132N/T209N) failed to generate genetically stable mutant viruses (Crabtree et al., 2004). Taken together, the findings suggest that at least one of the two $N$-glycosylation sites (probably N130) in NS1 protein is essential to produce viable virus. Similar to E protein, the impact of deglycosylation at this site varies depending on the virus strain and amino acid residue used for replacement.

\section{NS1 Protein Secretion}

In DENV, N130-glycosylation is important but not essential for NS1 secretion in mammalian cells (Despres et al., 1991; Jacobs et al., 1992; Pryor and Wright, 1994; Crabtree et al., 2004). Single and double NS1 mutant proteins are secreted from infected cells even though a reduced secretion yield has been observed (Crabtree et al., 2004; Somnuke et al., 2011). The impact of deglycosylation on secretion is thought to be associated with the stability of the NS1 oligomer. Mutation of N130 or N207 does not affect dimerization of the protein but compromises the stability of the dimer (Winkler et al., 1989; Pryor and Wright, 1994). The dimer appeared more heat sensitive when the $\mathrm{N}$-glycan was removed from the protein especially for N207A mutant. The use of tunicamycin, an enzyme targeting the host glycosylation enzymes, allowed confirm that absence of $\mathrm{N}$-glycan was solely responsible for the instability of NS1 oligomers instead of changes in the polypeptide backbone in the genetically deglycosylated mutants (Pryor and Wright, 1994; Flamand et al., 1999). Furthermore, the secretion of NS1 was reduced when complex glycans maturation was blocked by glycosylation inhibitors Swainsonine and 1-deoxymannojirimycin (Flamand et al., 1999). Consistently, low levels of NS1 with solely high mannose glycan are secreted from infected mosquito cells, which lack the enzymes to generate complex type glycans. These findings support the proposal that $N$-glycosylation and complex glycan are important for NS1 secretion (Hsieh and Robbins, 1984; Mason, 1989; Thiemmeca et al., 2016). In addition, the majority of the secreted WT and N207Q NS1 proteins are hexamers (Somnuke et al., 2011), whereas secreted N130Q and N130/N207Q NS1 proteins showed reduced hexamer population and increase in higher order oligomer $(>675 \mathrm{kDa})$ population. As compared to mammalian cell-secreted NS1, mosquito cell-secreted NS1 is less stable and undergoes degradation more rapidly at body temperature (Thiemmeca et al., 2016). Hence, the presence of complex glycan at N130 is critical for both NS1 secretion and NS1 hexamer stability (Flamand et al., 1999; Somnuke et al., 2011).

Similarly, it has been proposed that high-mannose glycans at N207 stabilizes NS1 dimer (Pryor et al., 1998; Flamand et al., 1999; Somnuke et al., 2011). Reduced levels of DENV 4 N207Q and N130Q/N207Q NS1 proteins were observed 


\begin{tabular}{|c|c|c|}
\hline NGC & IEAKLTNTTTDSRCPTQGEPSLNEEQDKRFVCKHSMVDRGWGNGCGLFGKGGIVTCAMFT & 120 \\
\hline PUO-218 & IEAKLTNTTTESRCPTQGEPSLNEEQDKRFVCKHSMVDRGWGNGCGLFGKGGIVTCAMFT & 120 \\
\hline 16681 & 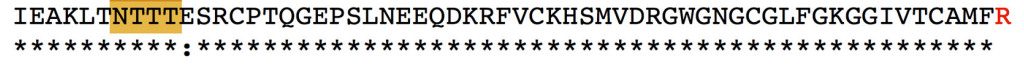 & 120 \\
\hline NGC & CKKNMKGKVVQPENLEYTIVITPHSGEEHAVGNDTGKHGKEIKITPQSSITEAELTGYGT & 180 \\
\hline PUO-218 & CKKNMEGKVVQPENLEYTIVVTPHSGEEHAVGNDTGKHGKEIKVTPQSSITEAELTGYGT & 180 \\
\hline 16681 & \multicolumn{2}{|l|}{ 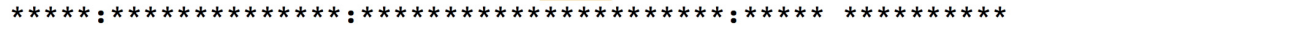 } \\
\hline \multicolumn{3}{|c|}{$\begin{array}{l}\text { FIGURE } 3 \text { Alignment of E protein sequences from multiple DENV } 2 \text { strains. N67 and N153 glycosylation motifs are highlighted in yellow. Strain } 16681 \text { differs fron } \\
\text { strain NGC and PUO-218 at position } 120 \text { and } 170 \text { (in red). Asterisk indicates positions which have a single, fully conserved residue; colon indicates conservation } \\
\text { between groups of strongly similar properties. }\end{array}$} \\
\hline
\end{tabular}

in culture supernatant (Somnuke et al., 2011) which could be explained by two possible scenari: (1) Stability of the secreted mutant forms is compromised due to a different protein conformation (Somnuke et al., 2011). The misfolding of the protein may lead to a less effective secretion of functional hexamer. (2) Transport of the protein from the perinuclear region is affected which in turn compromises the maturation and secretion of the protein (Crabtree et al., 2004).

\section{Virulence and immunogenicity}

Deglycosylated NS1 mutant viruses $\left(\mathrm{N} 130^{-}\right)$are less neurovirulent as evidenced by the reduced mortality observed with mice infected intracranially with the DENV2 and DENV4 mutants (Pletnev et al., 1993; Crabtree et al., 2004). The reduced neurovirulence of these viruses which lack the complex type glycans may be linked to the reduced levels of extracellular hexameric NS1 (Crabtree et al., 2004). The virulence phenotypes observed with ${\mathrm{N} 207^{-}}^{-}$mutant viruses varied depending on the DENV strain. DENV2 N207- mutant displayed decreased virulence (Pryor et al., 1998; Crabtree et al., 2004), whereas the DENV4 N207- mutant showed enhanced virulence in mice (Pletnev et al., 1993). The low to undetectable levels of NS1 specific antibodies in mice infected with the DENV4 N207mutant suggests that the enhanced neurovirulence could be attributed to the reduced immunogenicity of the virus (Pletnev et al., 1993).

\section{Complement Activation}

The complement cascade is the central defense mechanism of innate immunity which triggers the immune effector function to remove infectious pathogens and modified self cells upon activation. The activation and amplification of the complement pathway involves a series of sequential events and the whole process is tightly regulated. Complement can be activated through three major pathways, namely the classical, lectin and alternative pathways [reviewed in (Ricklin et al., 2016)]. The classical pathway is triggered by antibody-antigen complexes whereas the lectin pathway is activated by carbohydrate moieties on the microbial surface. The alternative pathway is activated through direct binding of $\mathrm{C} 3 \mathrm{~b}$ at the surface of pathogens, which results from the constitutive basal cleavage of C3 (Ricklin et al., 2016).
Mannose binding lectin (MBL) in the lectin pathway triggers antibody-independent activation of complement (Thielens et al., 2002). The proposed MBL-mediated virus elimination mechanisms include (1) direct virus neutralization, (2) C3/C4 deposition on virus surface and (3) interference of host cell lectin receptor binding (Liu et al., 2015). MBL differentiates self- from non-self-antigens based on a sugar density-dependent recognition mechanism (Dam and Brewer, 2010), and the micro pattern of the oligosaccharides structure in addition to the spatial geometry of the macro sugar pattern (Takahashi and Ezekowitz, 2005). It was proposed that the additional N67-glycan in DENV (which is absent in other flaviviruses) could promote a more efficient recognition and binding by MBL (Avirutnan et al., 2011). This hypothesis is supported by improved MBL binding and in vivo virus clearance of a genetically engineered WNV with additional N67-glycosylation site (Fuchs et al., 2010). $\mathrm{MBL}$ is reactive to high mannose oligosaccharides and thus can efficiently recognize insect cell-derived DENV with high mannose glycans present on its $\mathrm{E}$ proteins. Hence, the change of $N$-glycan profile of $\mathrm{E}$ protein after one round of replication in mammalian host cells may provide an opportunity to the virus to escape from effective $\mathrm{MBL}$ recognition (Fuchs et al., 2011). However, mammalian cell-derived DENV was found to be effectively inhibited and neutralized by mouse MBL (Fuchs et al., 2010). A separate study instead reported preferential binding of recombinant human $\mathrm{MBL}$ to insect cell-derived DENV2, whereas virions produced in monocyte-derived DC were not neutralized by human MBL (Avirutnan et al., 2011). It therefore remains unclear whether MBL-mediated virus clearance is optimally engaged during DENV infection in humans.

Furthermore, studies have shown that NS1 interferes with the complement pathway through binding to a number of its components (Muller and Young, 2013). N130Q NS1 was found to bind to $\mathrm{C} 1$ s proenzyme, $\mathrm{C} 1, \mathrm{C} 4$, and $\mathrm{C} 4 \mathrm{~b}$ with reduced affinity compared to WT and N207Q NS1 (Somnuke et al., 2011), indicating that the $N$-glycan is required for effective interaction with complement components. The role of NS1 glycosylation in the ability of the protein to interfere with the complement activation, however, has been largely ignored. The $N$-glycans were proposed to be involved in NS1 binding to C4 (Avirutnan et al., 2010) although direct experimental evidence has been missing. A recent study reported that 
secreted NS1 binds directly to C4BP, a major inhibitor of the C4b component (Thiemmeca et al., 2016). This binding leads to the recruitment of C4BP on cell surface via NS1 and inactivates $\mathrm{C} 4 \mathrm{~b}$ thereby interfering with the formation of the membrane attack complex (MAC). Furthermore, the work has demonstrated a competitive binding of NS1 to MBL, which prevents MBL-mediated DENV destruction. The presence of secreted NS1 in the saliva of Aedes mosquito suggests that secreted NS1 protein could help DENV to escape the host innate immune surveillance during virus transmission (Thiemmeca et al., 2016).

\section{Disease Pathogenesis}

Severe DEN (DHF/DSS) is characterized by increased vascular permeability and plasma leakage, thrombocytopenia, hemorrhagic fever and circulatory failure in DSS (WHO, 2017). The current paradigm proposes that viral-induced proinflammatory cytokine storm drives the disease progression to DHF/DSS (Pang et al., 2007). Direct interaction between DENV and CLEC5A expressed on macrophages indicates that virus glycosylation plays a role in DEN pathogenesis (Chen et al., 2008; Wu et al., 2013). Similar to the engagement to DC-SIGN, DENV binding to CLEC5A relies on sugar moieties and can be inhibited by exogenous fucose and mannose (Chen et al., 2008). However, CLEC5A binding does not mediate viral entry into the host cell, instead it serves as a cooperative signaling receptor to MR/DC-SIGN that activates macrophage inflammasome and triggers the production of pro-inflammatory cytokines (Chen et al., 2008; Wu et al., 2013; Lo et al., 2016). Consistently, anti-CLEC5A monoclonal antibody reduced DENV-induced vascular leakage in a mouse model (Chen et al., 2008), which further supports that targeting the viral glycoprotein-host lectin receptor interactions represents a potential therapeutic approach to counteract the excessive inflammatory responses involved in severe DEN.

\section{FUTURE PERSPECTIVES AND CONCLUSION}

Glycosylation is a post-translational modification which significantly affects the conformation of a protein. It is a heterogeneous process that is highly host-cell specific. Viruses have evolved to utilize their host's glycosylation machinery so as to optimize their fitness, infectivity, replication and virulence.

The role of glycosylation and glycan structures in DENV virulence has yet to be reported with evidence of attenuated phenotypes in symptomatic mouse models. Given the impact of glycosylation in virus entry and virus fitness in mammalian cells, it is highly likely that deglycosylated DENV mutants will display reduced virulence in vivo. The ability of Celgosivir treatment, a bicyclic iminosugar that inhibits glycosylation through negatively binding to ER [alpha]-glucosidase II, to protect mice from a lethal DENV challenge indirectly demonstrates the importance of glycosylation in DENV virulence (Perry et al., 2013; Sayce et al., 2016; Warfield et al., 2016).
To date, out of the eight DENV potential glycoproteins (Table 1), only E and NS1 proteins have been characterized from a glycosylation standpoint and not across all the DENV serotypes. Despite the biological importance of these structures being recognized, efforts to characterize the nature of the glycan structures in DENV have remained timid. There is for example little understanding of how glycosylation impacts DENV cell tropism where different glycan variants may influence binding of DENV to various host cell receptors and subsequent cell infection. Characterization of DENV glycoforms has been mainly performed in the mammalian cell line BHK-21 but no study has been conducted in more relevant primary mammalian cell types including Langerhans cells, monocytes, hepatocytes, and endothelial cells. Furthermore, in-depth characterization of the glycan structures using the latest glycomics technologies has yet to be reported for DENV. Associating the contribution of these glycans to the structure and ultimately function of the virion glycoproteins indeed requires glycomics and glycoproteomics. Such data need to be modeled using computational approaches as methods for crystallizing glycoproteins remains a complicated feat.

Furthermore, the role of glycosylation is also very important to recognize in biotherapeutic strategies. While substantial efforts have been devoted to developing neutralizing antibodies against DENV, the potency of these antibodies is largely dictated by the accessibility of the epitope that they target which can be influenced by the glycosylated status of the protein (Smith et al., 2013). Consistently, E protein glycosylation site has been reported to modulate the binding of neutralizing antibodies against a highly conserved, serotype cross-reactive epitope (Dejnirattisai et al., 2015). These challenges have prompted substantial investment into elucidating the three-dimensional conformation of the protein-antibody complexes and more importantly how glycosylation contributes to the tertiary and quaternary arrangements of the different glycoproteins on the virion. This approach is critical for the development of new therapeutics with broader activity and increased efficacy.

In conclusion, the DEN field as a whole would benefit greatly from in-depth understanding and characterization of the glycosylation patterns of DEN virions. With the recent technical advances in the fields of glycomics and glycoproteomics, this has become possible and will depend on productive interactions between glycobiologists and DEN virologists.

\section{AUTHOR CONTRIBUTIONS}

SY, TN-K, and SA wrote the manuscript. PR provided suggestions and edited the manuscript.

\section{FUNDING}

SA holds a research grant from the National Medical Research Council (NMRC/MOHIAFCAT2/007/2016) to develop dengue mouse models. 


\section{REFERENCES}

Acosta, E. G., Kumar, A., and Bartenschlager, R. (2014). Revisiting dengue virushost cell interaction: new insights into molecular and cellular virology. $A d v$. Virus Res. 88, 1-109. doi: 10.1016/B978-0-12-800098-4.00001-5

Akey, D. L., Brown, W. C., Dutta, S., Konwerski, J., Jose, J., Jurkiw, T. J., et al. (2014). Flavivirus NS1 structures reveal surfaces for associations with membranes and the immune system. Science 343, 881-885. doi: 10.1126/ science. 1247749

Alen, M. M. F., Dallmeier, K., Balzarini, J., Neyts, J., and Schols, D. (2012). Crucial role of the N-glycans on the viral E-envelope glycoprotein in DC-SIGNmediated dengue virus infection. Antiviral Res. 96, 280-287. doi: 10.1016/j. antiviral.2012.10.007

Allison, S. L., Schalich, J., Stiasny, K., Mandl, C. W., and Heinz, F. X. (2001). Mutational evidence for an internal fusion peptide in flavivirus envelope protein E. J. Virol. 75, 4268-4275. doi: 10.1128/JVI.75.9.4268-4275.2001

Allison, S. L., Schalich, J., Stiasny, K., Mandl, C. W., Kunz, C., and Heinz, F. X. (1995). Oligomeric rearrangement of tick-borne encephalitis virus envelope proteins induced by an acidic pH. J. Virol. 69, 695-700.

Avirutnan, P., Fuchs, A., Hauhart, R. E., Somnuke, P., Youn, S., Diamond, M. S., et al. (2010). Antagonism of the complement component C4 by flavivirus nonstructural protein NS1. J. Exp. Med. 207, 793-806. doi: 10.1084/jem. 20092545

Avirutnan, P., Hauhart, R. E., Marovich, M. A., Garred, P., Atkinson, J. P., and Diamond, M. S. (2011). Complement-mediated neutralization of dengue virus requires mannose-binding lectin. mBio, 2, e00276-11. doi: 10.1128/mBio. 00276- 11

Avirutnan, P., Zhang, L., Punyadee, N., Manuyakorn, A., Puttikhunt, C., Kasinrerk, W., et al. (2007). Secreted NS1 of dengue virus attaches to the surface of cells via interactions with heparan sulfate and chondroitin sulfate E. PLoS Pathog. 3:e183. doi: 10.1371/journal.ppat.0030183

Beatty, P. R., Puerta-Guardo, H., Killingbeck, S. S., Glasner, D. R., Hopkins, K. and Harris, E. (2015). Dengue virus NS1 triggers endothelial permeability and vascular leak that is prevented by NS1 vaccination. Sci. Transl. Med. 7, $304 \mathrm{ra} 141$. doi: 10.1126/scitranslmed.aaa3787

Boonnak, K., Slike, B. M., Burgess, T. H., Mason, R. M., Wu, S. J., Sun, P., et al. (2008). Role of dendritic cells in antibody-dependent enhancement of dengue virus infection. J. Virol. 82, 3939-3951. doi: 10.1128/JVI.02484-07

Bork, K., Horstkorte, R., and Weidemann, W. (2009). Increasing the sialylation of therapeutic glycoproteins: the potential of the sialic acid biosynthetic pathway. J. Pharm. Sci. 98, 3499-3508. doi: 10.1002/jps.21684

Brandt, W. E., Cardiff, R. D., and Russell, P. K. (1970). Dengue virions and antigens in brain and serum of infected mice. J. Virol. 6 500-506.

Bryant, J. E., Calvert, A. E., Mesesan, K., Crabtree, M. B., Volpe, K. E., Silengo, S., et al. (2007). Glycosylation of the dengue 2 virus E protein at N67 is critical for virus growth in vitro but not for growth in intrathoracically inoculated Aedes aegypti mosquitoes. Virology 366, 415-423. doi: 10.1016/j.virol.2007.05.007

Callewaert, N., Geysens, S., Molemans, F., and Contreras, R. (2001). Ultrasensitive profiling and sequencing of N-linked oligosaccharides using standard DNA-sequencing equipment. Glycobiology 11, 275-281. doi: 10.1093/glycob/ 11.4.275

Cambi, A., de Lange, F., van Maarseveen, N. M., Nijhuis, M., Joosten, B., van Dijk, E. M., et al. (2004). Microdomains of the C-type lectin DC-SIGN are portals for virus entry into dendritic cells. J. Cell Biol. 164, 145-155. doi: 10.1083/jcb. 200306112

Cambi, A., and Figdor, C. G. (2003). Dual function of C-type lectin-like receptors in the immune system. Curr. Opin. Cell Biol. 15, 539-546. doi: 10.1016/j.ceb. 2003.08.004

Capeding, M. R., Tran, N. H., Hadinegoro, S. R., Ismail, H. I., Chotpitayasunondh, T., Chua, M. N., et al. (2014). Clinical efficacy and safety of a novel tetravalent dengue vaccine in healthy children in Asia: a phase 3, randomised, observer-masked, placebo-controlled trial. Lancet 384, 1358-1365. doi: 10.1016/S0140-6736(14)61060-6

Chambers, T. J., Hahn, C. S., and Galler, R. (1990). Flavivirus genome organization, expression, and replication. Annu. Rev. Microbiol. 44, 649-688. doi: 10.1146/ annurev.mi.44.100190.003245

Chandler, K. B., Pompach, P., Goldman, R., and Edwards, N. (2013). Exploring sitespecific N-glycosylation microheterogeneity of haptoglobin using glycopeptide
CID tandem mass spectra and glycan database search. J. Proteome Res. 12, 3652-3666. doi: 10.1021/pr400196s

Chen, S. T., Lin, Y. L., Huang, M. T., Wu, M. F., Cheng, S. C., Lei, H. Y., et al. (2008). CLEC5A is critical for dengue-virus-induced lethal disease. Nature 453, 672-676. doi: 10.1038/nature07013

Courageot, M. P., Frenkiel, M. P., Dos Santos, C. D., Deubel, V., and Despres, P. (2000). Alpha-glucosidase inhibitors reduce dengue virus production by affecting the initial steps of virion morphogenesis in the endoplasmic reticulum. J. Virol. 74, 564-572. doi: 10.1128/JVI.74.1.564-572.2000

Crabtree, M. B., Kinney, R. M., and Miller, B. R. (2004). Deglycosylation of the NS1 protein of dengue 2 virus, strain 16681: Construction and characterization of mutant viruses. Arch. Virol. 150, 771-786. doi: 10.1007/s00705-0040430-8

Crill, W. D., and Roehrig, J. T. (2001). Monoclonal antibodies that bind to domain III of dengue virus $\mathrm{E}$ glycoprotein are the most efficient blockers of virus adsorption to Vero cells. J. Virol. 75, 7769-7773. doi: 10.1128/JVI.75.16.77697773.2001

Dam, T. K., and Brewer, C. F. (2010). Lectins as pattern recognition molecules: the effects of epitope density in innate immunity. Glycobiology 20, 270-279. doi: $10.1093 /$ glycob/cwp186

Dejnirattisai, W., Wongwiwat, W., Supasa, S., Zhang, X., Dai, X., Rouvinski, A., et al. (2015). A new class of highly potent, broadly neutralizing antibodies isolated from viremic patients infected with dengue virus. Nat. Immunol. 16, 170-177. doi: 10.1038/ni.3058

Dell, A., Galadari, A., Sastre, F., and Hitchen, P. (2010). Similarities and differences in the glycosylation mechanisms in prokaryotes and eukaryotes. Int. J. Microbiol. 2010:148178. doi: 10.1155/2010/148178

Despres, P., Girard, M., and Bouloy, M. (1991). Characterization of yellow fever virus proteins E and NS1 expressed in Vero and Spodoptera frugiperda cells. J. Gen. Virol. 72 (Pt 6), 1331-1342. doi: 10.1099/0022-1317-72-6-1331

Doores, K. J. (2015). The HIV glycan shield as a target for broadly neutralizing antibodies. FEBS J. 282, 4679-4691. doi: 10.1111/febs.13530

Dubayle, J., Vialle, S., Schneider, D., Pontvianne, J., Mantel, N., Adam, O., et al. (2015). Site-specific characterization of envelope protein N-glycosylation on Sanofi Pasteur\&apos;s tetravalent CYD dengue vaccine. Vaccine 33, 1360-1368. doi: 10.1016/j.vaccine.2015.01.047

Everest-Dass, A. V., Jin, D., Thaysen-Andersen, M., Nevalainen, H., Kolarich, D., and Packer, N. H. (2012). Comparative structural analysis of the glycosylation of salivary and buccal cell proteins: innate protection against infection by Candida albicans. Glycobiology 22, 1465-1479. doi: 10.1093/glycob/cws112

Falgout, B., Pethel, M., Zhang, Y. M., and Lai, C. J. (1991). Both nonstructural proteins NS2B and NS3 are required for the proteolytic processing of dengue virus nonstructural proteins. J. Virol. 65, 2467-2475.

Flamand, M., Megret, F., Mathieu, M., Lepault, J., Rey, F. A., and Deubel, V. (1999). Dengue virus type 1 nonstructural glycoprotein NS1 is secreted from mammalian cells as a soluble hexamer in a glycosylation-dependent fashion. J. Virol. 73, 6104-6110.

Fuchs, A., Lin, T.-Y., Beasley, D. W., Stover, C. M., Schwaeble, W. J., Pierson, T. C., et al. (2010). Direct complement restriction of flavivirus infection requires glycan recognition by mannose-binding lectin. Cell Host Microbe 8, 186-195. doi: 10.1016/j.chom.2010.07.007

Fuchs, A., Pinto, A. K., Schwaeble, W. J., and Diamond, M. S. (2011). The lectin pathway of complement activation contributes to protection from West Nile virus infection. Virology 412, 101-109. doi: 10.1016/j.virol.2011.01.003

Gould, E. A., Gallian, P., De Lamballerie, X., and Charrel, R. N. (2010). First cases of autochthonous dengue fever and chikungunya fever in France: from bad dream to reality!. Clin. Microbiol. Infect. 16, 1702-1704. doi: 10.1111/j.1469-0691.2010. 03386.x

Guirakhoo, F., Hunt, A. R., Lewis, J. G., and Roehrig, J. T. (1993). Selection and partial characterization of dengue 2 virus mutants that induce fusion at elevated pH. Virology 194, 219-223. doi: 10.1006/viro.1993.1252

Gutsche, I., Coulibaly, F., Voss, J. E., Salmon, J., dandapos;Alayer, J., Ermonval, M., et al. (2011). Secreted dengue virus nonstructural protein NS1 is an atypical barrel-shaped high-density lipoprotein. Proc. Natl. Acad. Sci. U.S.A. 108, 8003-8008. doi: 10.1073/pnas.1017338108

Guy, B., Briand, O., Lang, J., Saville, M., and Jackson, N. (2015). Development of the Sanofi Pasteur tetravalent dengue vaccine: One more step forward. Vaccine 33, 7100-7111. doi: 10.1016/j.vaccine.2015.09.108 
Guzman, M. G., Halstead, S. B., Artsob, H., Buchy, P., Farrar, J., Gubler, D. J., et al. (2010). Dengue: a continuing global threat. Nat. Rev. Microbiol. 8, S7-S16. doi: $10.1038 /$ nrmicro2460

Hacker, K., White, L., and de Silva, A. M. (2009). N-linked glycans on dengue viruses grown in mammalian and insect cells. J. Gen. Virol. 90, 2097-2106. doi: 10.1099/vir.0.012120-0

Halstead, S. B. (2014). Dengue antibody-dependent enhancement: knowns and unknowns. Microbiol. Spectr. 2, 249-271. doi: 10.1128/microbiolspec.AID0022-2014

Hart, G. W. (2013). Thematic minireview series on glycobiology and extracellular matrices: glycan functions pervade biology at all levels. J. Biol. Chem. 288, 6903. doi: $10.1074 /$ jbc.R113.453977

Harvey, D. J., Martin, R. L., Jackson, K. A., and Sutton, C. W. (2004). Fragmentation of N-linked glycans with a matrix-assisted laser desorption/ionization ion trap time-of-flight mass spectrometer. Rapid Commun. Mass Spectrom. 18, 2997-3007. doi: 10.1002/rcm.1709

Hase, T., Summers, P. L., and Cohen, W. H. (1989a). A comparative study of entry modes into C6/36 cells by Semliki Forest and Japanese encephalitis viruses. Arch. Virol. 108, 101-114.

Hase, T., Summers, P. L., and Eckels, K. H. (1989b). Flavivirus entry into cultured mosquito cells and human peripheral blood monocytes. Arch. Virol. 104, 129-143.

Houel, S., Hilliard, M., Yu, Y. Q., McLoughlin, N., Martin, S. M., Rudd, P. M., et al. (2014). N- and O-glycosylation analysis of etanercept using liquid chromatography and quadrupole time-of-flight mass spectrometry equipped with electron-transfer dissociation functionality. Anal. Chem. 86, 576-584. doi: $10.1021 /$ ac402726h

Hsieh, P., and Robbins, P. W. (1984). Regulation of asparagine-linked oligosaccharide processing. Oligosaccharide processing in Aedes albopictus mosquito cells. J. Biol. Chem. 259, 2375-2382.

Hsu, T. A., Takahashi, N., Tsukamoto, Y., Kato, K., Shimada, I., Masuda, K., et al. (1997). Differential N-glycan patterns of secreted and intracellular IgG produced in Trichoplusia ni cells. J. Biol. Chem. 272, 9062-9070. doi: 10.1074/ jbc.272.14.9062

Huang, C. Y., Butrapet, S., Moss, K. J., Childers, T., Erb, S. M., Calvert, A. E., et al. (2010). The dengue virus type 2 envelope protein fusion peptide is essential for membrane fusion. Virology 396, 305-315. doi: 10.1016/j.virol.2009.10.027

Hung, S. E. A. (1999). Analysis of the steps involved in dengue virus entry into host cells. Virology 257, 156-167. doi: 10.1006/viro.1999.9633

Ishak, H., Takegami, T., Kamimura, K., and Funada, H. (2001). Comparative sequences of two type 1 dengue virus strains possessing different growth characteristics in vitro. Microbiol. Immunol. 45, 327-331. doi: 10.1111/j.13480421.2001.tb02627.x

Jacobs, S. C., Stephenson, J. R., and Wilkinson, G. W. (1992). High-level expression of the tick-borne encephalitis virus NS1 protein by using an adenovirus-based vector: protection elicited in a murine model. J. Virol. 66, 2086-2095.

Johnson, A. J., Guirakhoo, F., and Roehrig, J. T. (1994). The envelope glycoproteins of dengue 1 and dengue 2 viruses grown in mosquito cells differ in their utilization of potential glycosylation sites. Virology 203, 241-249. doi: 10.1006/ viro.1994.1481

Kliks, S. C., Nisalak, A., Brandt, W. E., Wahl, L., and Burke, D. S. (1989). Antibodydependent enhancement of dengue virus growth in human monocytes as a risk factor for dengue hemorrhagic fever. Am. J. Trop. Med. Hyg. 40, 444-451. doi: 10.4269/ajtmh.1989.40.444

Kolarich, D., Jensen, P. H., Altmann, F., and Packer, N. H. (2012). Determination of site-specific glycan heterogeneity on glycoproteins. Nat. Protoc. 7, 1285-1298. doi: 10.1038/nprot.2012.062

Konishi, E., and Mason, P. W. (1993). Proper maturation of the Japanese encephalitis virus envelope glycoprotein requires cosynthesis with the premembrane protein. J. Virol. 67, 1672-1675.

Kubelka, V., Altmann, F., Kornfeld, G., and Marz, L. (1994). Structures of the $\mathrm{N}$-linked oligosaccharides of the membrane glycoproteins from three lepidopteran cell lines (Sf-21, IZD-Mb-0503, Bm-N). Arch. Biochem. Biophys. 308, 148-157. doi: 10.1006/abbi.1994.1021

Kubelka, V., Altmann, F., Staudacher, E., Tretter, V., Marz, L., Hard, K., et al. (1993). Primary structures of the N-linked carbohydrate chains from honeybee venom phospholipase A2. Eur. J. Biochem. 213, 1193-1204. doi: 10.1111/j.14321033.1993.tb17870.x
Kuhn, R. J., Zhang, W., Rossmann, M. G., Pletnev, S. V., Corver, J., Lenches, E., et al. (2002). Structure of dengue virus: implications for flavivirus organization, maturation, and fusion. Cell 108, 717-725. doi: 10.1016/S0092-8674(02)0 0660-8

Land, A., and Braakman, I. (2001). Folding of the human immunodeficiency virus type 1 envelope glycoprotein in the endoplasmic reticulum. Biochimie 83, 783-790. doi: 10.1016/S0300-9084(01)01314-1

Lee, E., Leang, S. K., Davidson, A., and Lobigs, M. (2010). Both E protein glycans adversely affect dengue virus infectivity but are beneficial for virion release. J. Virol. 84, 5171-5180. doi: 10.1128/jvi.01900-09

Lee, E., Weir, R. C., and Dalgarno, L. (1997). Changes in the dengue virus major envelope protein on passaging and their localization on the three-dimensional structure of the protein. Virology 232, 281-290. doi: 10.1006/viro.1997.8570

Lei, Y., Yu, H., Dong, Y., Yang, J., Ye, W., Wang, Y., et al. (2015). Characterization of N-glycan structures on the surface of mature dengue 2 virus derived from insect cells. PLoS ONE 10:e0132122. doi: 10.1371/journal.pone.0132122

Li, J., Bhuvanakantham, R., Howe, J., and Ng, M. -L. (2006). The glycosylation site in the envelope protein of West Nile virus (Sarafend) plays an important role in replication and maturation processes. J. Gen. Virol. 87, 613-622. doi: 10.1099/vir.0.81320-0

Li, L., Lok, S. M., Yu, I. -M., Zhang, Y., Kuhn, R. J., Chen, J., et al. (2008). Structure of the immature dengue virus at Low $\mathrm{pH}$ primes proteolytic maturation. Science 319, 1830-1834. doi: 10.1126/science.1153264

Liu, Y., Liu, J., Pang, X., Liu, T., Ning, Z., and Cheng, G. (2015). The roles of direct recognition by animal lectins in antiviral immunity and viral pathogenesis. Molecules 20, 2272-2295. doi: 10.3390/molecules20022272

Lo, Y. L., Liou, G. G., Lyu, J. H., Hsiao, M., Hsu, T. L., and Wong, C. H. (2016). Dengue virus infection is through a cooperative interaction between a mannose receptor and CLEC5A on macrophage as a multivalent hetero-complex. PLoS ONE 11:e0166474. doi: 10.1371/journal.pone.0166474

Lorenz, I. C., Allison, S. L., Heinz, F. X., and Helenius, A. (2002). Folding and dimerization of tick-borne encephalitis virus envelope proteins prM and E in the endoplasmic reticulum. J. Virol. 76, 5480-5491. doi: 10.1128/JVI.76.11. 5480-5491.2002

Mackenzie, J. M., Jones, M. K., and Young, P. R. (1996). Immunolocalization of the dengue virus nonstructural glycoprotein NS1 suggests a role in viral RNA replication. Virology 220, 232-240. doi: 10.1006/viro.1996.0307

Marino, K., Bones, J., Kattla, J. J., and Rudd, P. M. (2010). A systematic approach to protein glycosylation analysis: a path through the maze. Nat. Chem. Biol. 6, 713-723. doi: $10.1038 /$ nchembio.437

Mason, P. W. (1989). Maturation of Japanese encephalitis virus glycoproteins produced by infected mammalian and mosquito cells. Virology 169, 354-364. doi: 10.1016/0042-6822(89)90161-X

Medina, R. A., Stertz, S., Manicassamy, B., Zimmermann, P., Sun, X., Albrecht, R. A., et al. (2013). Glycosylations in the globular head of the hemagglutinin protein modulate the virulence and antigenic properties of the H1N1 influenza viruses. Sci. Transl. Med. 5, 187ra170. doi: 10.1126/scitranslmed.3005996

Meunier, J. C., Fournillier, A., Choukhi, A., Cahour, A., Cocquerel, L., Dubuisson, J., et al. (1999). Analysis of the glycosylation sites of hepatitis C virus (HCV) glycoprotein E1 and the influence of E1 glycans on the formation of the HCV glycoprotein complex. J. Gen. Virol. 80 (Pt 4), 887-896. doi: 10.1099/00221317-80-4-887

Miller, J. L., de Wet, B. J., Martinez-Pomares, L., Radcliffe, C. M., Dwek, R. A., Rudd, P. M., et al. (2008). The mannose receptor mediates dengue virus infection of macrophages. PLoS Pathog. 4:e17. doi: 10.1371/journal.ppat. 0040017

Miller, S., Kastner, S., Krijnse-Locker, J., Buhler, S., and Bartenschlager, R. (2007). The non-structural protein $4 \mathrm{~A}$ of dengue virus is an integral membrane protein inducing membrane alterations in a $2 \mathrm{~K}$-regulated manner. J. Biol. Chem. 282, 8873-8882. doi: 10.1074/jbc.M609919200

Mir-Shekari, S. Y., Ashford, D. A., Harvey, D. J., Dwek, R. A., and Schulze, I. T. (1997). The glycosylation of the influenza A virus hemagglutinin by mammalian cells. A site-specific study. J. Biol. Chem. 272, 4027-4036. doi: 10.1074/jbc.272. 7.4027

Modhiran, N., Watterson, D., Muller, D. A., Panetta, A. K., Sester, D. P., Liu, L., et al. (2015). Dengue virus NS1 protein activates cells via Toll-like receptor 4 and disrupts endothelial cell monolayer integrity. Sci. Transl. Med. 7, 304ra142. doi: $10.1126 /$ scitranslmed.aaa3863 
Modis, Y., Ogata, S., Clements, D., and Harrison, S. C. (2003). A ligand-binding pocket in the dengue virus envelope glycoprotein. Proc. Natl. Acad. Sci. U.S.A. 100, 6986-6991. doi: 10.1073/pnas.0832193100

Modis, Y., Ogata, S., Clements, D., and Harrison, S. C. (2004). Structure of the dengue virus envelope protein after membrane fusion. Nature 427, 313-319. doi: $10.1038 /$ nature 02165

Mondotte, J. A., Lozach, P. Y., Amara, A., and Gamarnik, A. V. (2007). Essential role of dengue virus envelope protein $\mathrm{N}$ glycosylation at asparagine-67 during viral propagation. J. Virol. 81, 7136-7148. doi: 10.1128/JVI.00116-07

Muller, D. A., Landsberg, M. J., Bletchly, C., Rothnagel, R., Waddington, L., Hankamer, B., et al. (2012). Structure of the dengue virus glycoprotein nonstructural protein 1 by electron microscopy and single-particle analysis. J. Gen. Virol. 93, 771-779. doi: 10.1099/vir.0.039321-0

Muller, D. A., and Young, P. R. (2013). The flavivirus NS1 protein: molecular and structural biology, immunology, role in pathogenesis and application as a diagnostic biomarker. Antiviral Res. 98, 192-208. doi: 10.1016/j.antiviral.2013. 03.008

Mysling, S., Palmisano, G., Hojrup, P., and Thaysen-Andersen, M. (2010). Utilizing ion-pairing hydrophilic interaction chromatography solid phase extraction for efficient glycopeptide enrichment in glycoproteomics. Anal. Chem. 82, 5598-5609. doi: 10.1021/ac100530w

Navarro-Sanchez, E., Altmeyer, R., Amara, A., Schwartz, O., Fieschi, F., Virelizier, J. L., et al. (2003). Dendritic-cell-specific ICAM3-grabbing non-integrin is essential for the productive infection of human dendritic cells by mosquitocell-derived dengue viruses. EMBO Rep. 4, 723-728. doi: 10.1038/sj.embor. embor866

Nguyen-Khuong, T., Everest-Dass, A. V., Kautto, L., Zhao, Z., Willcox, M. D., and Packer, N. H. (2015). Glycomic characterization of basal tears and changes with diabetes and diabetic retinopathy. Glycobiology 25, 269-283. doi: 10.1093/ glycob/cwu 108

Palmisano, G., Larsen, M. R., Packer, N. H., and Thaysen-Andersen, M. (2013). Structural analysis of glycoprotein sialylation - part II: LC-MS based detection. RSC Adv. 3, 22706-22726. doi: 10.1039/C3RA42969E

Pang, T., Cardosa, M. J., and Guzman, M. G. (2007). Of cascades and perfect storms: the immunopathogenesis of dengue haemorrhagic fever-dengue shock syndrome (DHF/DSS). Immunol. Cell Biol. 85, 43-45. doi: 10.1038/sj.icb. 7100008

Park, E. I., Mi, Y., Unverzagt, C., Gabius, H. J., and Baenziger, J. U. (2005). The asialoglycoprotein receptor clears glycoconjugates terminating with sialic acid alpha 2,6GalNAc. Proc. Natl. Acad. Sci. U.S.A. 102, 17125-17129. doi: 10.1073/ pnas.0508537102

Perry, S. T., Buck, M. D., Plummer, E. M., Penmasta, R. A., Batra, H., Stavale, E. J., et al. (2013). An iminosugar with potent inhibition of dengue virus infection in vivo. Antiviral Res. 98, 35-43. doi: 10.1016/j.antiviral.2013.01.004

Pickles, R. J., Fahrner, J. A., Petrella, J. M., Boucher, R. C., and Bergelson, J. M. (2000). Retargeting the coxsackievirus and adenovirus receptor to the apical surface of polarized epithelial cells reveals the glycocalyx as a barrier to adenovirus-mediated gene transfer. J. Virol. 74, 6050-6057. doi: 10.1128/JVI. 74.13.6050-6057.2000

Pletnev, A. G., Bray, M., and Lai, C. J. (1993). Chimeric tick-borne encephalitis and dengue type 4 viruses: effects of mutations on neurovirulence in mice. J. Virol. 67, 4956-4963.

Pokidysheva, E., Zhang, Y., Battisti, A. J., Bator-Kelly, C. M., Chipman, P. R., Xiao, C., et al. (2006). Cryo-EM reconstruction of dengue virus in complex with the carbohydrate recognition domain of DC-SIGN. Cell 124, 485-493. doi: 10.1016/j.cell.2005.11.042

Pryor, M. J., Gualano, R. C., Lin, B., Davidson, A. D., and Wright, P. J. (1998). Growth restriction of dengue virus type 2 by site-specific mutagenesis of virusencoded glycoproteins. J. Gen. Virol., 79 (Pt 11), 2631-2639. doi: 10.1099/00221317-79-11-2631

Pryor, M. J., and Wright, P. J. (1993). The effects of site-directed mutagenesis on the dimerization and secretion of the NS1 protein specified by dengue virus. Virology 194, 769-780. doi: 10.1006/viro.1993.1318

Pryor, M. J., and Wright, P. J. (1994). Glycosylation mutants of dengue virus NS1 protein. J. Gen. Virol. 75 (Pt 5), 1183-1187. doi: 10.1099/0022-1317-75-5-1183

Putnak, J. R., Charles, P. C., Padmanabhan, R., Irie, K., Hoke, C. H., and Burke, D. S. (1988). Functional and antigenic domains of the dengue-2 virus nonstructural glycoprotein NS-1. Virology 163, 93-103. doi: 10.1016/0042-6822(88)90236-X
Rendic, D., Linder, A., Paschinger, K., Borth, N., Wilson, I. B., and Fabini, G. (2006). Modulation of neural carbohydrate epitope expression in Drosophila melanogaster cells. J. Biol. Chem. 281, 3343-3353. doi: 10.1074/jbc.M508 334200

Rendić, D., Wilson, I., and Paschinger, K. (2008). The glycosylation capacity of insect cells. Croat. Chem. Acta 81, 7-21. doi: 10.1038/375291a0

Rey, F. A., Heinz, F. X., Mandl, C., Kunz, C., and Harrison, S. C. (1995). The envelope glycoprotein from tick-borne encephalitis virus at 2 A resolution. Nature 375, 291-298. doi: 10.1111/j.1742-4658.2006.05239.x

Rhomberg, S., Fuchsluger, C., Rendic, D., Paschinger, K., Jantsch, V., Kosma, P., et al. (2006). Reconstitution in vitro of the GDP-fucose biosynthetic pathways of Caenorhabditis elegans and Drosophila melanogaster. FEBS J. 273, 2244-2256. doi: 10.1111/j.1742-4658.2006.05239.x

Ricklin, D., Reis, E. S., and Lambris, J. D. (2016). Complement in disease: a defence system turning offensive. Nat. Rev. Nephrol. 12, 383-401. doi: 10.1038/nrneph. 2016.70

Rodrigues, J. A., Acosta-Serrano, A., Aebi, M., Ferguson, M. A., Routier, F. H., Schiller, I., et al. (2015). Parasite glycobiology: a bittersweet symphony. PLoS Pathog. 11:e1005169. doi: 10.1371/journal.ppat.1005169

Rudd, P. M., Downing, A. K., Cadene, M., Harvey, D. J., Wormald, M. R., Weir, I., et al. (2000). Hybrid and complex glycans are linked to the conserved $\mathrm{N}$-glycosylation site of the third eight-cysteine domain of LTBP-1 in insect cells. Biochemistry 39, 1596-1603. doi: 10.1021/bi9918285

Rudd, P. M., and Dwek, R. A. (1997). Rapid, sensitive sequencing of oligosaccharides from glycoproteins. Curr. Opin. Biotechnol. 8, 488-497. doi: 10.1016/S0958-1669(97)80073-0

Sayce, A. C., Alonzi, D. S., Killingbeck, S. S., Tyrrell, B. E., Hill, M. L., Caputo, A. T., et al. (2016). Iminosugars inhibit dengue virus production via inhibition of ER Alpha-Glucosidases-not glycolipid processing enzymes. PLoS Negl. Trop. Dis. 10:e0004524. doi: 10.1371/journal.pntd.0004524

Schmitz, J., Roehrig, J., Barrett, A., and Hombach, J. (2011). Next generation dengue vaccines: a review of candidates in preclinical development. Vaccine 29, 7276-7284. doi: 10.1016/j.vaccine.2011.07.017

Scott, N. E., Parker, B. L., Connolly, A. M., Paulech, J., Edwards, A. V., Crossett, B., et al. (2011). Simultaneous glycan-peptide characterization using hydrophilic interaction chromatography and parallel fragmentation by CID, higher energy collisional dissociation, and electron transfer dissociation MS applied to the N-linked glycoproteome of Campylobacter jejuni. Mol. Cell. Proteomics 10, M000031-MCP201. doi: 10.1074/mcp.M000031-MCP201

Shi, X., and Jarvis, D. L. (2007). Protein N-glycosylation in the baculovirus-insect cell system. Curr. Drug Targets 8, 1116-1125. doi: 10.2174/1389450077821 51360

Shinya, K., Ebina, M., Yamada, S., Ono, M., Kasai, N., and Kawaoka, Y. (2006). Avian flu: influenza virus receptors in the human airway. Nature 440, 435-436. doi: $10.1038 / 440435 \mathrm{a}$

Slater-Handshy, T., Droll, D. A., Fan, X., Di Bisceglie, A. M., and Chambers, T. J. (2004). HCV E2 glycoprotein: mutagenesis of N-linked glycosylation sites and its effects on E2 expression and processing. Virology 319, 36-48. doi: 10.1016/j. virol.2003.10.008

Smith, G. W., and Wright, P. J. (1985). Synthesis of proteins and glycoproteins in dengue type 2 virus-infected vero and Aedes albopictus cells. J. Gen. Virol. 66 (Pt 3), 559-571. doi: 10.1099/0022-1317-66-3-559

Smith, S. A., de Alwis, A. R., Kose, N., Harris, E., Ibarra, K. D., Kahle, K. M., et al. (2013). The potent and broadly neutralizing human dengue virus-specific monoclonal antibody $1 \mathrm{C} 19$ reveals a unique cross-reactive epitope on the bc loop of domain II of the envelope protein. MBio. 4:e873-e813. doi: 10.1128/ mBio.00873-13

Somnuke, P., Hauhart, R. E., Atkinson, J. P., Diamond, M. S., and Avirutnan, P. (2011). N-linked glycosylation of dengue virus NS1 protein modulates secretion, cell-surface expression, hexamer stability, and interactions with human complement. Virology 413, 253-264. doi: 10.1016/j.virol.2011. 02.022

Stadler, K., Allison, S. L., Schalich, J., and Heinz, F. X. (1997). Proteolytic activation of tick-borne encephalitis virus by furin. J. Virol. 71, 8475-8481.

Staudacher, E., Altmann, F., Marz, L., Hard, K., Kamerling, J. P., and Vliegenthart, J. F. (1992). Alpha 1-6(alpha 1-3)-difucosylation of the asparagine-bound $\mathrm{N}$-acetylglucosamine in honeybee venom phospholipase A2. Glycoconj. J. 9, 82-85. doi: 10.1007/BF00731703 
Stavenhagen, K., Hinneburg, H., Kolarich, D., and Wuhrer, M. (2017). Site-specific $\mathrm{N}$ - and O-glycopeptide analysis using an integrated C18-PGC-LC-ESI-QTOFMS/MS approach. Methods Mol. Biol. 1503, 109-119. doi: 10.1007/978-1-49396493-2_9

Suhrbier, A., and La Linn, M. (2003). Suppression of antiviral responses by antibody-dependent enhancement of macrophage infection. Trends Immunol. 24, 165-168. doi: 10.1016/S1471-4906(03)00065-6

Sumer-Bayraktar, Z., Kolarich, D., Campbell, M. P., Ali, S., Packer, N. H., and Thaysen-Andersen, M. (2011). N-glycans modulate the function of human corticosteroid-binding globulin. Mol. Cell. Proteomics 10, M111.009100. doi: 10.1074/mcp.M111.009100

Tajima, S., Takasaki, T., and Kurane, I. (2008). Characterization of Asn130-toAla mutant of dengue type 1 virus NS1 protein. Virus Genes 36, 323-329. doi: 10.1007/s11262-008-0211-7

Takahashi, K., and Ezekowitz, R. A. (2005). The role of the mannose-binding lectin in innate immunity. Clin. Infect. Dis. 41 Suppl 7, S440-S444. doi: 10.1086/ 431987

Takahashi, N., Tsukamoto, Y., Shiosaka, S., Kishi, T., Hakoshima, T., Arata, Y., et al. (1999). N-glycan structures of murine hippocampus serine protease, neuropsin, produced in Trichoplusia ni cells. Glycoconj. J. 16, 405-414. doi: 10.1023/A: 1007082612019

Tassaneetrithep, B., Burgess, T. H., Granelli-Piperno, A., Trumpfheller, C., Finke, J., Sun, W., et al. (2003). DC-SIGN (CD209) mediates dengue virus infection of human dendritic cells. J. Exp. Med. 197, 823-829. doi: 10.1084/jem.200 21840

Thaysen-Andersen, M., Packer, N. H., and Schulz, B. L. (2016). Maturing glycoproteomics technologies provide unique structural insights into the $\mathrm{N}$-glycoproteome and its regulation in health and disease. Mol. Cell. Proteomics 15, 1773-1790. doi: 10.1074/mcp.O115.057638

Thielens, N. M., Tacnet-Delorme, P., and Arlaud, G. J. (2002). Interaction of C1q and mannan-binding lectin with viruses. Immunobiology 205, 563-574. doi: 10.1078/0171-2985-00155

Thiemmeca, S., Tamdet, C., Punyadee, N., Prommool, T., Songjaeng, A., Noisakran, S., et al. (2016). Secreted NS1 protects dengue virus from mannose-binding lectin-mediated neutralization. J. Immunol. 197, 4053-4065. doi: 10.4049/jimmunol.1600323

Varki, A., Cummings, R. D., Esko, J. D., Stanley, P., Hart, G., Aebi, M., et al. (2015). Essentials of Glycobiology. Cold Spring Harbor NY: Cold Spring Harbor Laboratory Press.

Vaughn, D. W., Green, S., Kalayanarooj, S., Innis, B. L., Nimmannitya, S., Suntayakorn, S., et al. (2000). Dengue viremia titer, antibody response pattern, and virus serotype correlate with disease severity. J. Infect. Dis. 181, 2-9. doi: $10.1086 / 315215$

Vercoutter-Edouart, A. S., Slomianny, M. C., Dekeyzer-Beseme, O., Haeuw, J. F., and Michalski, J. C. (2008). Glycoproteomics and glycomics investigation of membrane N-glycosylproteins from human colon carcinoma cells. Proteomics 8, 3236-3256. doi: 10.1002/pmic.200800151

Vigerust, D. J., and Shepherd, V. L. (2007). Virus glycosylation: role in virulence and immune interactions. Trends Microbiol. 15, 211-218. doi: 10.1016/j.tim. 2007.03.003

Villar, L., Dayan, G. H., Arredondo-Garcia, J. L., Rivera, D. M., Cunha, R., Deseda, C., et al. (2015). Efficacy of a tetravalent dengue vaccine in children in Latin America. N. Engl. J. Med. 372, 113-123. doi: 10.1056/NEJMoa1411037

Walls, A. C., Tortorici, M. A., Frenz, B., Snijder, J., Li, W., Rey, F. A., et al. (2016). Glycan shield and epitope masking of a coronavirus spike protein observed by cryo-electron microscopy. Nat. Struct. Mol. Biol. 23, 899-905. doi: 10.1038/ nsmb. 3293

Walther, T., Karamanska, R., Chan, R. W., Chan, M. C., Jia, N., Air, G., et al. (2013). Glycomic analysis of human respiratory tract tissues and correlation with influenza virus infection. PLoS Pathog. 9:e1003223. doi: 10.1371/journal. ppat. 1003223

Wang, S., He, R., and Anderson, R. (1999). PrM- and cell-binding domains of the dengue virus E protein. J. Virol. 73, 2547-2551.
Warfield, K. L., Plummer, E. M., Sayce, A. C., Alonzi, D. S., Tang, W., Tyrrell, B. E., et al. (2016). Inhibition of endoplasmic reticulum glucosidases is required for in vitro and in vivo dengue antiviral activity by the iminosugar UV-4. Antiviral Res. 129, 93-98. doi: 10.1016/j.antiviral.2016.03.001

Westaway, E. G., and Goodman, M. R. (1987). Variation in distribution of the three flavivirus-specified glycoproteins detected by immunofluorescence in infected Vero cells. Arch. Virol. 94, 215-228. doi: 10.1007/BF01310715

WHO (2017). Dengue Control [Online]. Available at: http://www.who.int/ denguecontrol/en/

Winkler, G., Maxwell, S. E., Ruemmler, C., and Stollar, V. (1989). Newly synthesized dengue-2 virus nonstructural protein NS1 is a soluble protein but becomes partially hydrophobic and membrane-associated after dimerization. Virology 171, 302-305. doi: 10.1016/0042-6822(89)90544-8

Winkler, G., Randolph, V. B., Cleaves, G. R., Ryan, T. E., and Stollar, V. (1988). Evidence that the mature form of the flavivirus nonstructural protein NS1 is a dimer. Virology 162, 187-196. doi: 10.1016/0042-6822(88)90408-4

Wu, M. F., Chen, S. T., Yang, A. H., Lin, W. W., Lin, Y. L., Chen, N. J., et al. (2013). CLEC5A is critical for dengue virus-induced inflammasome activation in human macrophages. Blood 121, 95-106. doi: 10.1182/blood-2012-05-430090

Xie, X., Zou, J., Puttikhunt, C., Yuan, Z., and Shi, P. Y. (2015). Two distinct sets of NS2A molecules are responsible for dengue virus RNA synthesis and virion assembly. J. Virol. 89, 1298-1313. doi: 10.1128/JVI.02882-14

Yang, Y., Liu, F., Franc, V., Halim, L. A., Schellekens, H., and Heck, A. J. (2016). Hybrid mass spectrometry approaches in glycoprotein analysis and their usage in scoring biosimilarity. Nat Commun. 7:13397. doi: 10.1038/ncomms 13397

Yoshii, K., Yanagihara, N., Ishizuka, M., Sakai, M., and Kariwa, H. (2013). $\mathrm{N}$-linked glycan in tick-borne encephalitis virus envelope protein affects viral secretion in mammalian cells, but not in tick cells. J. Gen. Virol. 94, 2249-2258. doi: 10.1099/vir.0.055269-0

Youn, S., Li, T., McCune, B. T., Edeling, M. A., Fremont, D. H., Cristea, I. M., et al. (2012). Evidence for a genetic and physical interaction between nonstructural proteins NS1 and NS4B that modulates replication of West Nile virus. J. Virol. 86, 7360-7371. doi: 10.1128/JVI.00157-12

Yu, I. M., Holdaway, H. A., Chipman, P. R., Kuhn, R. J., Rossmann, M. G., and Chen, J. (2009). Association of the pr peptides with dengue virus at acidic $\mathrm{pH}$ blocks membrane fusion. J. Virol. 83, 12101-12107. doi: 10.1128/JVI.01637-09

Yu, I. M., Zhang, W., Holdaway, H. A., Li, L., Kostyuchenko, V. A., Chipman, P. R., et al. (2008). Structure of the immature dengue virus at low $\mathrm{pH}$ primes proteolytic maturation. Science 319, 1834-1837. doi: 10.1126/science.1153264

Zelensky, A. N., and Gready, J. E. (2005). The C-type lectin-like domain superfamily. FEBS J. 272, 6179-6217. doi: 10.1111/j.1742-4658.2005.05031.x

Zhang, P., Woen, S., Wang, T., Liau, B., Zhao, S., Chen, C., et al. (2016). Challenges of glycosylation analysis and control: an integrated approach to producing optimal and consistent therapeutic drugs. Drug Discov. Today 21, 740-765. doi: 10.1016/j.drudis.2016.01.006

Zhang, Y., Corver, J., Chipman, P. R., Zhang, W., Pletnev, S. V., Sedlak, D., et al. (2003). Structures of immature flavivirus particles. EMBO J. 22, 2604-2613. doi: $10.1093 / \mathrm{emboj} / \mathrm{cdg} 270$

Zhang, Y., Zhang, W., Ogata, S., Clements, D., Strauss, J. H., Baker, T. S., et al. (2004). Conformational changes of the flavivirus E glycoprotein. Structure. 12, 1607-1618. doi: 10.1016/j.str.2004.06.019

Conflict of Interest Statement: The authors declare that the research was conducted in the absence of any commercial or financial relationships that could be construed as a potential conflict of interest.

Copyright (c) 2017 Yap, Nguyen-Khuong, Rudd and Alonso. This is an open-access article distributed under the terms of the Creative Commons Attribution License (CC BY). The use, distribution or reproduction in other forums is permitted, provided the original author(s) or licensor are credited and that the original publication in this journal is cited, in accordance with accepted academic practice. No use, distribution or reproduction is permitted which does not comply with these terms. 